\title{
Dengue Vaccines: Challenge and Confrontation
}

\author{
Guey Chuen Perng ${ }^{1,2,3 *}$, Huan-Yao Lei ${ }^{2,3}$, Yee-Shin Lin ${ }^{2,3}$, Kulkanya Chokephaibulkit ${ }^{4}$ \\ ${ }^{1}$ Department of Pathology and Laboratory Medicine, Emory Vaccine Center, Emory University School of Medicine, Atlanta, USA; \\ ${ }^{2}$ Department of Microbiology and Immunology, National Cheng Kung University Medical College, Tainan, Taiwan; ${ }^{3}$ Center of In- \\ fectious Disease and Signaling Research, National Cheng Kung University, Tainan, Taiwan; ${ }^{4}$ Department of Pediatrics, Faculty of \\ Medicine Siriraj Hospital, Mahidol University, Bangkok, Thailand. \\ Email: *gperng@emory.edu
}

Received September $20^{\text {th }}, 2011$; revised October $14^{\text {th }}, 2011$; accepted November $7^{\text {th }}, 2011$.

\begin{abstract}
Dengue has been recognized as one of the most important vector-borne human diseases. The disease is induced by dengue virus infection resulting from the bite of an infected Aedes spp. mosquito after imbibing the tainted blood from animals or patients. Dynamic clinical spectrums ranging from asymptomatic, undifferentiated fever, typical dengue fever (DF), dengue hemorrhagic fever (DHF) and dengue shock syndrome (DSS) have been well documented. Initially, the disease was mainly restricted in tropical and subtropical zones. However, with factors such as ineffective vector control, frequency of human migration, unplanned urbanization, and changing climate temperature, the disease has been spotted at almost every territory of the earth. Dengue has been associated with human disease for more than two centuries. Although classic DF is viewed as a self-limited illness, subjects normally resolve within two weeks and recover without any noticeable complications or sequelae, some of these infected individuals may progress to lifethreatening DHF/DSS, characterized with plasma leakage due to an increase in capillary permeability. The significantly increased public health threat and the burden of morbidity and mortality of dengue globally has caught the attention of public officials and prompted an action to find a way to contain and prevent the disease. The lack of specific dengue therapeutics has led to an emphasis on vaccine development, one of the best and effective strategies to reduce and prevent the illness. Making a dengue vaccine has been attempted more than six decades; although some of these products are in clinical trials, vaccine development for the prevention of dengue disease is still at its infancy. So far no dengue vaccine is available for the public. Dengue vaccine development may be hindered by the complexity of the clinical presentations, which implicates that multiple pathogenic mechanisms are involved in dengue disease. Some of these elements will be discussed in the current review. Opening up discussion on these pros and cons and engaging in more research to understand these features would not only improve the understanding of the pathogenesis of the dengue virus infection but also pave a new tactic to develop a safer and effective dengue vaccine.
\end{abstract}

Keywords: Flavivirus, Dengue Fever, DHF, Dengue Vaccine

\section{Introduction}

Dengue is induced by infection with dengue virus and is one of the most important arthropod-borne human diseases. Although human beings are the natural host for the virus, it is transmitted by the bite of an Aedes spp. mosquito carrying infectious virus. Initially, the distribution of the disease was mainly in the tropical and subtropical regions. But, over time numerous factors such as global warming and increased frequency of human migration, and ineffective vector control have resulted in the expansion of dengue virus to almost every corner of the earth [1]. Consequently, dengue has become an important public health burden and threat. In order to mitigate the likely escalating public health threat, vaccine development is urgently needed to prevent the further spread of disease. Although several foreseeable and perspective dengue vaccines are in the pipelines and some of which have been advanced to clinical trials, many questions and mysteries remain unanswered. There are several recent articles dealing with the dengue vaccine development strategies including preclinical and clinical studies [2-8], which will not be further discussed in this article. The current article addresses some of the critical pros and cons that are underappreciated and are perhaps highly relevant to the pathogenesis of dengue virus infection. Understanding these elements can further facilitate the design of a better dengue vaccine. 


\section{Dengue}

\subsection{Epidemiology}

Dengue is introduced into the host during the blood meal taken by an infected mosquito. Epidemiological studies suggest that about 2.5 billion or $2 / 5$ of the world's population are at risk, of which approximately 1 billion live in tropical and subtropical regions. It is also estimated that about 50 million infections occur annually, roughly causing 500,000 hospitalizations, mainly in children. The case fatality rate is $1 \%-2 \%$ in most dengue hyperendemic countries, but the rate of more than $5 \%$ has been reported in some areas [1]. The dengue vaccine, when available, would be a major advance in reducing the burden of health threat and controlling the disease globally.

\subsection{Modes of Transmission}

Dengue virus is introduced to the human host by the bite of infected mosquitoes. Mosquitoes first become infected with dengue virus by feeding on the blood of a dengue-infected person. Several factors influence the rate of successful transmission, ranging from environmental temperature, density of Aedes spp. mosquitoes, competence of the mosquitoes, and levels of viremia in the host, interruption in exploration, deposition of the virus, and the pulse of the host [9]. Vector control measures would be one of the legitimate options to limit the spread of dengue virus in the environment. Although traditionally, the measures are viewed very costly and not effective; recently, population-replacement approaches in regions that have sporadic dengue transmission seemed to be a success $[10,11]$. However, whether these feats are effective in highly endemic regions remain to be further tested.

\subsection{Burden of Dengue}

Dengue has a significant impact on the economy and society and burdens the public health sectors in endemic areas. Globally, the societal burden has been estimated to be approximately 528 to 1300 disability-adjusted life years (DALY) per million to populations in endemic regions [12-15]. Children appear to be the most vulnerable group in many highly endemic countries and hence contribute the greatest number of DALYs attributable to dengue in the Torrid Zone. With more than a half-million cases reported annually, the average aggregate annual economic cost of dengue for eight study countries in the Americas and Asia is at approximate $\$ 587$ million [14].

\subsection{Clinical Presentations}

Dengue virus infections cause a spectrum of illnesses ranging from asymptomatic, mild undifferentiated fever to classical dengue fever (DF), and dengue hemorrhagic fever (DHF). DHF is classified as grades 1 to 4 depending on the severity [16]. These dynamic clinical manifestations are well-known. The initial clinical presentations of the classical DF are very similar to that of DHF, making the differential diagnosis of severe DHF very challenging to the attending physicians. The unique feature that differentiates DHF from DF is the capillary leakage [16]. In general, the onset of DF and DHF is very abrupt, beginning with fever. The common initial symptoms at the febrile stage are headache, malaise, weakness, chilliness, pains and aches, and gastrointestinal symptoms. The physical examination reveals flushing of the face (Figure 1(A)), lethargy, irritablility (in young children), abdominal pain, hepatomegaly, and the presence of petechial hemorrhages or other bleeding manifestations. Initial complete blood count reveals leucopenia, and after 2 - 5 days of fever, thrombocytopenia and depletion of coagulation factors may develop, suggestive of a process of generalized consumptive coagulopathy [17]. In DF, the fever abates after 3 - 7 days and the patients recover. In DHF, however, the progression of intravascular fluid leakage occurs after 3 - 5 days of fever. This is the so-called critical stage, when the fever typically decreases and the patients' condition is at its worst. At this point many patients may develop shock from depletion of intravascular volume and bleeding. This stage lasts no more than 48 hours and then the patients recover. Frequently confluent petechial convalescent rashes with scattered sparing spots develop (Figure 1(B)). Atypical or abnormal clinical presentations have been reported such as encephalopathy, severe hepatitis, and myocarditis [15]. WHO defines DF as a syndrome including at least two of the following manifestations: headache, retroorbital pain, myalgia, arthralgia/ joint pain, rash, hemorrhagic manifestations such as presence of petechiae or positive tourniquet test, and leucopenia (wbc $\leq 5000$ cells $/ \mathrm{ml}$ ). For DHF diagnosis, the presence of intravascular fluid leakage that leads to its depletion and bleeding diathesis are both required. The WHO case definition of DHF includes all of the following conditions: high continuous fever of $2-7$ days, hemorrhagic manifestations such as petechiae or positive tourniquet test, platelet count $\leq 100,000$ cells $/ \mathrm{ml}$, and evidence of plasma leakage such as rising haematocrit $\geq 20 \%$ of baseline, and the presence of pleural effusion or ascites. DHF grade 3 and 4 , presenting with depletion of intravascular volume leading to shock, are classified as DSS. This WHO classification has been mostly adequate and used for many decades; however there have been occasional difficulties in classifying patients who present with unusual manifestations, some of which have severe disease but do not fit the DHF definition. In 2009, WHO published another case classification system for guiding dengue manage- 

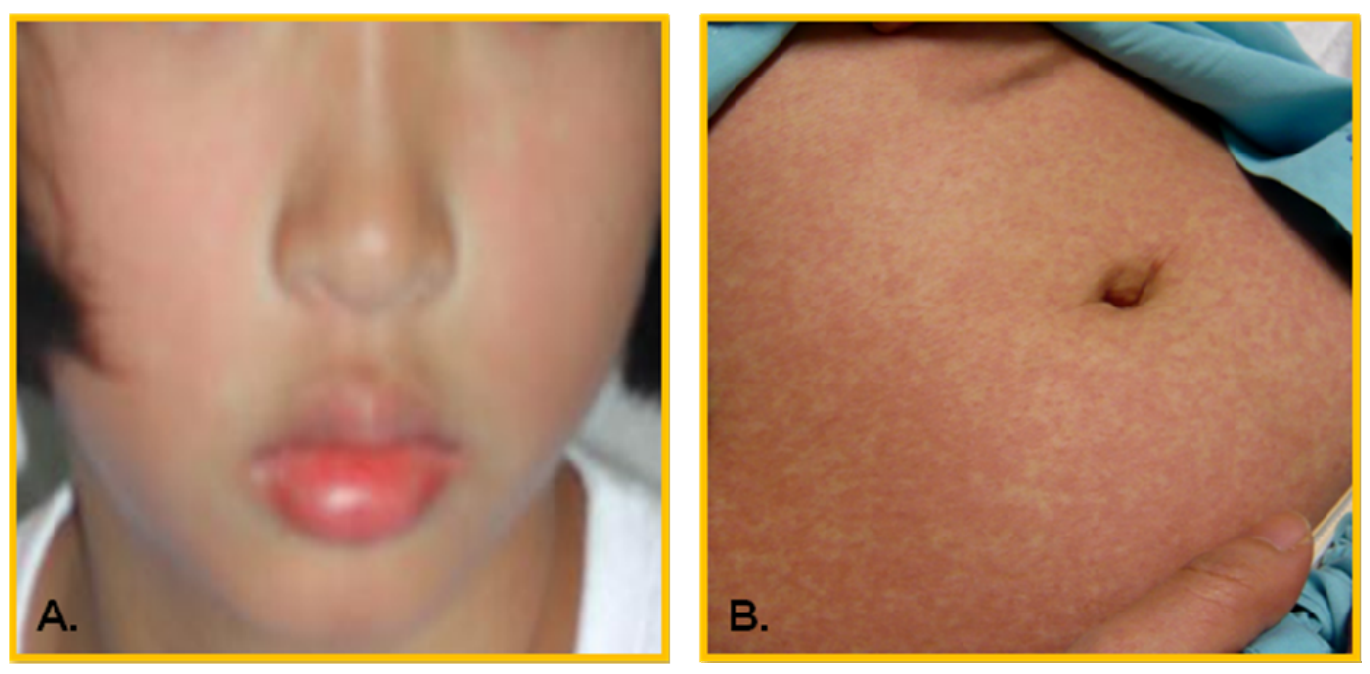

Figure 1. Typical cutaneous presentations in dengue patient. (A) In febrile stage: flushing face and mild rash. Petechiae is also common; (B) In convalescent stage: erythematous maculopapular rash with petechiae on face, trunk, and extremities. The eruption becomes confluent, with small, round islands of sparing, so call white islands in a sea of red. According to the guidelines defined by WHO [16], a tourniquet test, determining capillary fragility, is positive if there are 20 or more petechiae per square inch.

ment [15]. This new classification includes dengue without warning signs, dengue with warning signs, and severe dengue, with improved sensitivity for detection $[18,19]$. However, it was not widely adopted in many settings and most of the surveillance systems still use the old classification of DF and DHF.

\subsection{Management}

The principle management of dengue cases is supportive or palliative care with close monitoring for shock and bleeding. The prompt and appropriate intravenous fluid therapy is the key to obtaining successful outcomes. Severe disease progresses rapidly but generally ceases by 48 hours after the critical stage. There has been no specific treatment or antiviral approved for therapy.

\section{Dengue Virus Biology}

\subsection{Biology of the Virus}

Dengue virus is in the family of Flaviviridae and under the genus Flavivirus, which includes Yellow Fever and West Nile Viruses. Though all these viruses are transmitted by mosquitoes, they differ in their primary host reservoir. Dengue primarily resides in humans, while animals and birds are the principal hosts for the Yellow Fever Virus and the West Nile Virus, respectively. The genome of dengue virus is single-stranded, positive-sense RNA with approximately 11,000 nucleotides. The RNA is infectious since it is capable of functioning as mRNA even though only equipped with a 5 ' terminus type I cap (m7GpppAmp) but lack of 3' terminus poly-A tail
[20-22]. The genome encodes a single large open reading frame protein that is proteolytically cleaved into 10 known proteins consisting of 3 structural proteins, capsid (C), membrane (prM) and envelope (E), and 7 nonstructural proteins (NS) $[23,24]$. The arrangement and the order of the gene products is C-prM-E-NS1-NS2ANS2B-NS3-NS4A-NS4B-NS5 $[25,26]$. The functions of the proteins encoded by the virus and its importance in the life cycle of the virus in tissue culture system have been investigated very well and are not the focus of the current review. The readers are directed to these recent comprehensive review articles on the subject [2,5,27].

\subsection{Dynamic Viral Particles in Infected Hosts}

It has been known for a while that there are two variations of the dengue virion derived from different hosts. The lipid-associated viral particles, originally described in infected mouse brains, sediment slower through sucrose while having the same buoyant density as mousederived classical virions. The classical/conventional viral particles typically observed in fibroblast, lymphoblast or mosquito cell cultures, have a slightly heavier density [28, 29]. The earliest documentation on the diversity of the infectious dengue virus was addressed by Paul et al. [30]. Pooled samples of infected human serum obtained from patients acutely ill with dengue were preserved in a frozen state and then thawed and separated into two fractions, top and bottom, by differential centrifugation. Subsequently each fraction was inoculated into chimpanzees and both were found to contain infectious virus. Based on structural investigations, two types of viral par- 
ticles are observed, mature and immature virions, in tissue culture. The former contains $M$ protein, while the latter contains precursor $\mathrm{M}$ (prM), which is proteolytically cleaved during maturation to yield M $[31,32]$. However, based on the density gradients, two types of particles also exist, classical and lipid associated viral particles [33-35]. The classical viral particles have a density of $1.22-1.24 \mathrm{~g} / \mathrm{ml}$, and sediment to the bottom of the gradient, while the lipid-associated particles are lighter, at a density of $1.18-1.19 \mathrm{~g} / \mathrm{ml}$, and remain in the upper portion of the gradient after centrifugation [33,34]. The big difference between the two particles is the integration of the capsid protein, which appears not to be present in the lipid-associated form [35]. Interestingly, it has been reported that hepatitis C viral RNA is associated with exosomes integrated with envelope proteins as well [36]. As a whole, the capsid structure within the lipid envelope of the dengue virion is not well resolved, suggesting that the core protein is poorly ordered or that the arrangement of the capsid structure itself is variable in relation to the external envelope structures.

\subsection{Multiple Serotypes}

Dengue viruses can be classified into four different antigenically distinct serotypes, a unique feature that distinguishes them from other flaviviruses. Each of the serotype is capable of inducing the spectrum of dengue diseases. Multiple dengue serotypes can co-circulate in endemic areas [37]. These dengue viral serotypes can be further classified into different genotypes based on nucleotide variation [38-40]. Different genotypes within a serotype have been correlated with the levels of virulence [41]. Additionally, structural differences in some strains of virus have been linked to different cell tropisms and may determine disease severity [42]. Consequently, one of the biggest concerns in dengue vaccine development is the existence of the multiple serotypes [43]. Although it is the general belief that homotypic vaccination could provide a lifetime of protective immunity, the hard data has not been obtained. In addition, the dynamic antibodies produced as a consequence of vaccination with any strain may result in unfavorable outcomes due to the activity of non-protective, cross-reacting enhanced antibodies. Currently, there is no available diagnostic tool that can differentiate sequential infection by different dengue serotypes [44].

\section{Pathogenesis of Dengue}

\subsection{Timing of Disease}

Despite its importance in human morbidity and mortality and decades of intensive efforts to learn and understand dengue, its pathogenesis remains a major enigma. Sam- ples or specimens obtained from dengue patients are always at a late stage of the illness (Figure 2). Analysis of the results could be very difficult and perhaps misleading. Fever is the major element in subjects that has been shown to be highly correlated with viremia [45], but its significance in integration of data analysis, or use as adjustment to reflect the time of the sample collection, has not been well documented. The average incubation period is 5.66 days with $84 \%$ between 4 and 7 days [46, 47].

\subsection{Viral Tropism}

In tissue culture, various cells have been demonstrated to be permissive for dengue virus infection [48]. Also, virus has been isolated from various organs of autopsy specimens such as bone marrow, midbrain, spleen, liver, lymph node, and kidney, and dengue antigen has been demonstrated in lymphoid cells of the spleen and thymus, necrotic tissue of liver, reticulo-endothelial region of the thymus, lymph nodes, liver, spleen, lung and skin [49-51]. Only on one occasion was viral RNA observed in liver [52]. Considering the high levels of viremia in dengue patients and the phagocytic nature of the cells in these organs, it is not clear such cells represent adsorbed, ingested, or replicating virus since isolation of virus is a rare event from these tissues. Suggestively, isolations of dengue viruses in organ suspensions do not constitute evidence of virus replication in those tissues. Recovered viruses could have resulted from the contamination of the organ by viremic blood. Coincidently, dengue virus has been observed mainly replicating in cells derived from the bone marrow and not in cells apart of the secondary immune system, such as spleen, lymph node and thymus [53]. This could lend the hypothesis that an early site of dengue virus replication is in the bone marrow [54-56]. Scientifically, the paucity of successful virus isolations from tissues obtained at autopsy $[49-51,57,58]$ is an argument in favor of dengue being a post-infection immune-mediated phenomenon $[37,59,60]$. Although it is the general belief that the cells of the mononuclear phagocytic lineage are the main site of replication of dengue virus in man [59], evidence to support this contention is far from conclusive. Consequently, it is still unclear which tissues and cells dengue viruses replicate in man.

\subsection{Immune-Mediated Pathogenesis}

The severity of dengue diseases are observed not at the time when the viral burden is at its highest in vivo, but rather when the virus is being rapidly cleared from host tissues by the innate and adaptive immune responses. It is critical to bear in mind that evidence suggests that dengue viral antigen in leukocytes are most likely seen 


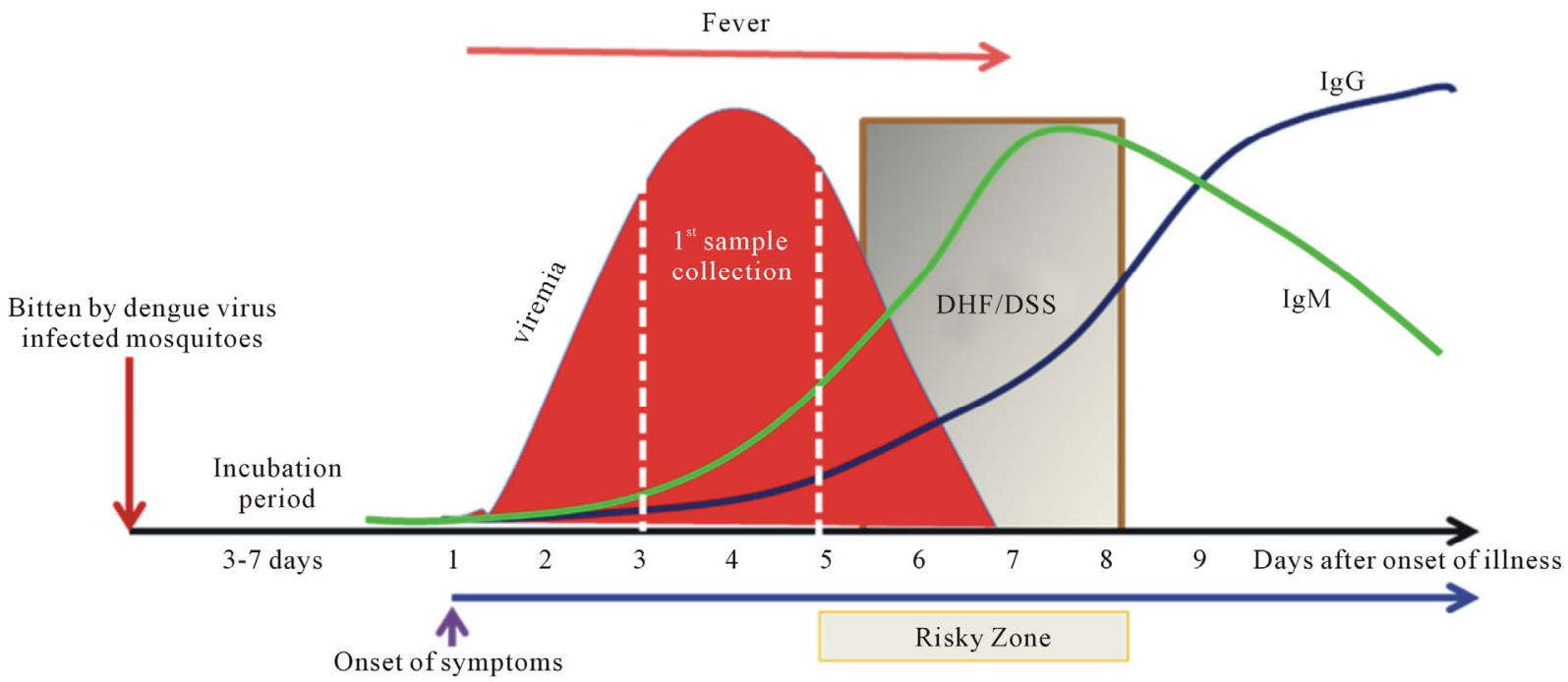

Figure 2. Sequential events of dengue. Dengue is a timing disease resulting from the infection of dengue viruses transmitted by Aedes spp. mosquitoes. The incubation time after the bite of the mosquito is about 3 to 7 days followed by the onset of fever, likely at the beginning of viremia as well. The affected patients do not normally seek help within the first couple days of fever. Consequently, by the time the patient shows up at the clinic or hospital, viremia is often at its peak or decreasing when the first sample is taken. The fever lasts for about 5 to 7 days. The risky zone is at the defervescent stage; severe DHF associated with DSS may occur during this window period. In primary infections, the IgM is detectable during the risky zone period, followed by IgG. In secondary or re-infections, the sequences of disease development share the same path as the primary infection, except that IgG is readily detectable during the risky zone era. Clearly, dengue is an acute infectious disease since patients normally recover within two weeks without having noticeable sequelae.

after the cessation of viremia, based upon studies in rhesus monkeys [61]. This has led to the suggestion that the pathogenesis of clinically important complications is closely linked to the host immune response $[37,60]$. The observations that the host response to dengue virus infection could be manifested as classical dengue and DHF, in conjunction with the epidemiological facts that cases of DHF are more likely to occur in individuals who experience a secondary heterotypic dengue virus infection, lead to the consideration that this immunological mechanism may be important in DHF, lending the hypothesis of antibody-dependent enhancement (ADE) [62,63]. However, neutralizing antibody assays are not suited for distinguishing between a primary dengue virus infected patient from a secondary, tertiary or quaternary exposure [64]. Since a reliable tool is not available to standardize this neutralization assay, inconsistencies abound in the literature on this hypothesis. For example, an overt dengue disease has been observed in subjects demonstrating a preexisting neutralizing antibody to a dengue viral serotype when they are infected with the similar virus strain [65]. However, severe dengue virus infections occur in the absence of a preexisting dengue immune profile as well [66-68]. Very recently, a lack of an association between enhancing maternal antibodies and the development of severe dengue (DHF) in infants has been reported [69]. This study has called for the rethinking or refinement of the current ADE theory of DHF in infancy. Consequently, dengue pathogenesis remains to be further explored.

Immune viral antigen-antibody complexes have been consistently identified in the plasma of patients with the hemagglutination-inhibition method [70]. Importantly, platelet-associated immunoglobulin $\mathrm{M}$ or $\mathrm{G}$ has been documented in dengue patients [71-73]. Additionally, increased phagocytosis of platelets from patients with secondary dengue virus infection by human macrophages has been reported [74]. Furthermore, it is suggested that the platelet adhesiveness and aggregations are related to the presence of viral antigen-antibody complexes in the patient's immune cells $[75,76]$. Nevertheless, the significance of the platelet-immune complex-leukocyte aggregates has not been addressed in these investigations.

\subsection{Other Factors}

The timing and dynamic spectrum of dengue disease indicates that many factors whether they are sequential, synergistic, or simultaneous occurring events contribute to the clinical outcomes. Intrinsic factors, such as individual's genetic background, age, race, and sex and extrinsic elements, such as nutritional status, underlying illness, viral virulence, pre-existing antibodies, interval between first and subsequent infection, and the sequence of infections may influence pathogenesis [77]. 


\section{Animal Models}

\subsection{History of Animal Investigations for Dengue Virus}

Upon discovery that dengue virus is transmitted by the mosquitoes that imbibe blood from dengue infected individuals, there were attempts to reproduce the disease in small animals [78]. Many animals, more than 500 species, were inoculated with contaminated blood but none of these animals could be infected by the virus and present with the classical signs of human dengue [46,79]. Although rodents, such as mice or guinea pigs, seem to be susceptible to infection with dengue virus, classical human dengue is not observed in these animals [80-82]. In addition, the biological properties of the virus are significantly altered, resulting in differences between the input and the output virus, especially concerning the virulence phenotypes $[81,83]$.

\subsection{Small Animals}

An animal model that can recapitulate the cardinal features of human dengue currently does not exist and is urgently needed. Nonetheless, laboratory animals, such as mice and other rodents, are somewhat susceptible to dengue virus infection and currently utilized for experimental infections; under certain settings, various disease models have been described in mice [84-88]. Although these models display some features of human dengue disease, they each have significant limitations $[85,89]$. For example, these models have mostly relied upon mouse-adapted viruses that appear to be attenuated with respect to human infection $[81,83]$, and often present with a distinct paralysis phenotype, uncharacteristic of human disease [85]. The 'humanized' mouse model that lacks the murine antibody response and demonstrates some dengue symptoms is a step closer to the desired small animal model needed for research purposes [90-92]. As of yet, this model has not yielded new insights into dengue virus-specific immune responses.

\subsection{Nonhuman Primates}

Systemic research suggests that the nonhuman primate immune system and its responses, including profiles to dengue virus infection, are very similar to that of human beings. Chimpanzees and monkeys have been found to be highly susceptible for dengue virus infection, though the cardinal features present in human disease are hardly seen in these infected animals $[30,46]$. Therefore, humans, monkeys and chimpanzees are viewed to be the natural hosts for dengue virus. Subsequent investigations have revealed that the viremia levels in the circulation of monkeys and chimps are significantly lowered than that of infected humans [93]. Further studies established that viral load is highly associated with the severity of dengue symptoms [94]. Recently, some clinical manifestations, for example, coagulopathy and hemorrhage have been reproduced by administration of a high dose of virus to rhesus monkey intravenously [95]. This animal therefore could provide a useful tool to test the immunological responses to dengue vaccine and a good model to study some of the aspects of dengue pathogenesis seen in man.

\section{Dengue Vaccine History}

Development of dengue vaccine has been attempted for more than 6 decades. A chronicle milestone on the activities is given in Figure 3.

\subsection{Era Prior to WWII, 1917-1940}

The earliest literature describing the modulation of dengue virus virulence was by Cleland et al. [78], in which they intended to culture virus through a series of injections into human volunteers in order to study certain aspects of dengue fever. They had successfully passed successively through four generations of artificial dengue cases, but a doubtful positive case was recorded in the fifth passage. This was the very first indication that an attenuated dengue virus strain could be obtained with successive passage in a host. This paved the way for Blanc and Caminopetros [96] who pursued production of an attenuated living virus that would give rise to lowgrade symptomless dengue with subsequent immunity. Simmons et al. attempted to generate an attenuated or killed dengue vaccine by successively passaging the virus in mosquitoes and/or treatments with anti-serum and desiccation [46]. St. John and Holt attempted to produce killed vaccine by phenol extract from infected monkey liver and spleen [97]. Holt and Kintner intended to generate a killed dengue vaccine by utilizing X-ray irradiation with infected mosquitoes [98]. The dengue vaccine development was interrupted when WWII erupted.

\subsection{During and Post WWII Era, 1940-1960}

The quest for a dengue vaccine was not stagnated during and after WWII. Although dengue has been shown to be caused by a filterable agent $[47,99]$, the first dengue virus was not isolated until 1940, during WWII, by Dr. Hotta, S. in Japan and by Dr. Sabin, A.B. in the US [80-83]. During this period several innovative techniques were invented and developed. This offered a good opportunity to study dengue vaccine in much more specific manner. Several attempts to alter the virulence of the isolated dengue virus were made as well. These included studies of the immune response in mice using formalin-inactivated and attenuated dengue vaccines derived from suckling mice [80,100-102]. Sabin also observed that immunity elicited in volunteers who received the live 


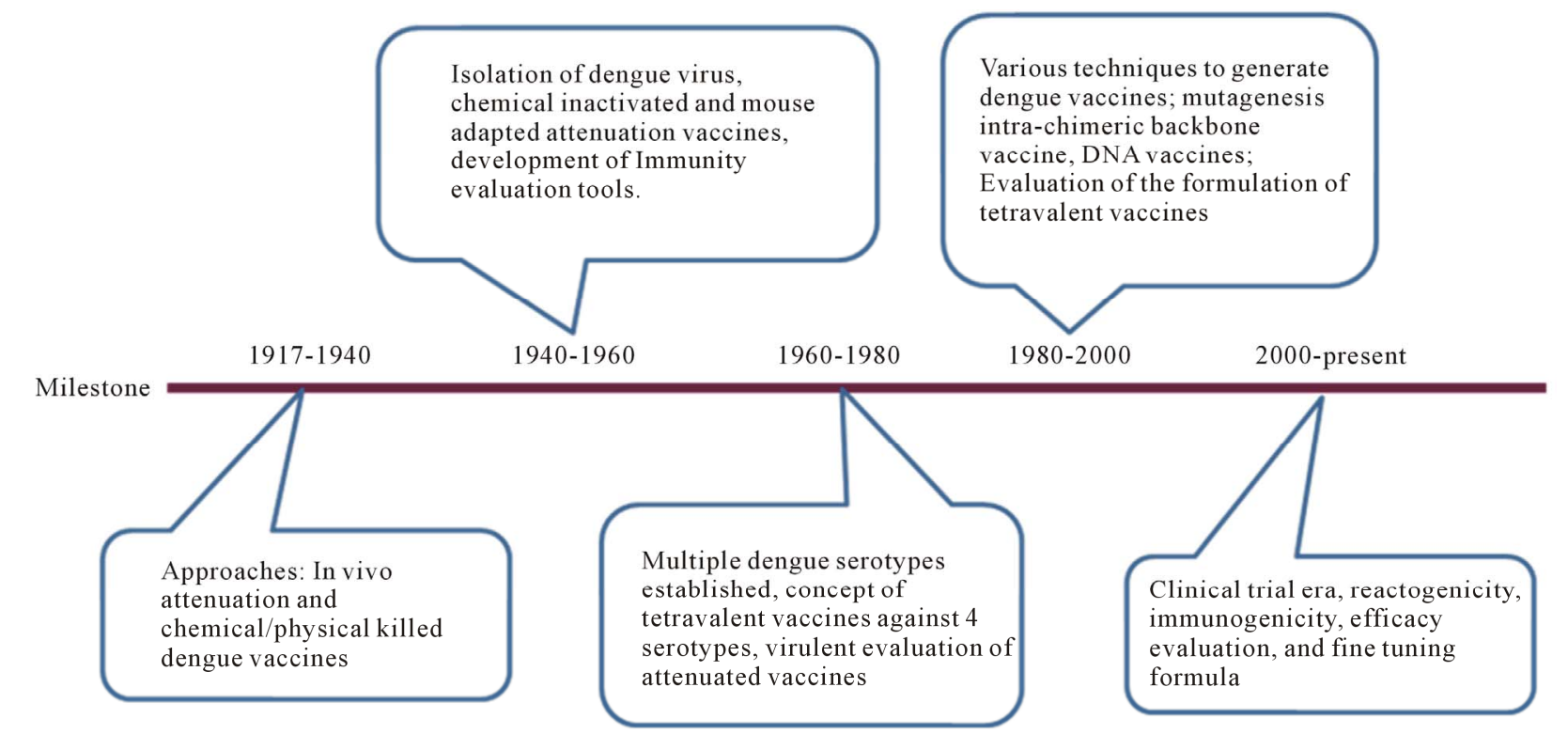

Figure 3. A chronicle milestone of dengue vaccine development. The history of dengue vaccine development is segmented according to the milestone achieved in each era. These milestones are 1917-1940, 1940-1960, 1960-1980, 1980-2000, and 2000-present. Critical achievements are briefly addressed for each era.

attenuated dengue vaccine could sustain the re-infection with the same dengue serotype at least for 18 months [81]. The first dengue vaccine field trial was conducted in the Caribbean [103]. However, further studies revealed that the live attenuated dengue vaccines produced from the mouse brain were not ideal for use in humans.

The isolation of the virus had significantly contributed to the development of biological and functional assays allowing for the study of immune responses to dengue virus. These new tools and techniques included the neutralization assay [81], complement fixation test [30], serological measurement of immunity in mice [80] and in man [101], and tests analyzing the immune response in patients [81]. The neutralization assays and complement test also led to an understanding that multiple dengue serotypes existed and that possibly the immune response to one type interfered with the development of the others when co-administered simultaneously [81].

\subsection{Major Milestone Era, 1960-1980}

The major milestone from this era was that multiple serotypes of dengue virus were firmly established and designated as DENV1, DENV2, DENV3, and DENV4 [104]. Researchers gained their first glimpse on the pathogenicity of dengue hemorrhagic fever when specimens became available during the late 1950s and early 1960s [105]. Dengue transmission also dramatically increased, leading to the rise in the incidence of DF and the emergence of epidemic DHF in South-East Asia after WWII [106]. All these factors contributed to the changes in policy making and guideline crafting for the development of dengue vaccines, which was another major milestone from this period [107]. The first priority was to develop a live attenuated vaccine for all four dengue virus serotypes. These attenuated vaccines were derived from serial passages in PDK cells. The safety of the attenuated viruses was a concern since there was no good animal model to evaluate the virulence of the vaccine candidates. However, a general agreement on the criteria for attenuation markers was established. After plaque purification of virus from LLC-MK2 cells, confirming the lack of neurovirulence in suckling mice as well as determining temperature sensitivity and the absence of CPE in LLC-MK2 cells were performed. If these standards were met, then the candidate vaccine was then tested for neurovirulence in monkeys by intracerebral inoculation [108].

\subsection{Golden Milestone Era, 1980-2000}

This era brought about many golden milestones for dengue vaccine researchers. The numerous techniques and strategies employed to generate a variety of dengue vaccines have recently been reviewed [2-5,109]. These candidates include mutant, chimera, subunit, and DNA vaccines. Even though over- or under-attenuated dengue vaccines developed under sponsorship of the U.S. Army proved not to be ideal for use in humans [110,111], some of them moved rapidly (at the speed of light) through safety, reactogenicity, and immunogenicity clinical trials. The safety and immunogenicity data obtained from these 
phase 1 clinical trials with monovalent vaccines in nonimmune volunteers revealed mixed results $[112,113]$. However, as a whole, the live attenuated vaccine did not show severe adverse reactions, the seroconversion rate was remarkable with very low virus doses, and neutralizing antibodies were still detectable one year later with just one dose [114]. Hence, it was concluded that the monovalent vaccine is probably as good as yellow fever $17 \mathrm{D}$ vaccine in terms of safety and immunogenicity.

A series of bivalent, trivalent, and tetravalent clinical trials were carried out for about a decade in both immune and non-immune young adults and in children residing in the endemic country of Thailand $[113,115,116]$. As a whole, the results were acceptable and efforts were shifted to find the best formulation for the four attenuated vaccine viruses to provide the best immunogenicity for all four serotypes. However, problems with antibody production due to interference among the different serotypes in the formulation are the major concern.

\subsection{Clinical Trial Era, 2000-Present}

This era focused on bringing forward these established vaccines into clinical trials as soon as possible. A few set backs were encountered; for instance, one of the tetravalent live attenuated vaccines were shelved due to the imbalance in the antibody response to each serotype and consistent presence of high reactogenicity [108]. While some continued to search for the right composition for formulation of tetravalent vaccine [117], a new strategy for vaccine development was introduced [109,118-120]. Consequently, clinical trials evaluating vaccine safety and immunogenicity in conjunction with the search for the right formulation for the tetravalent chimeric vaccine have dominated the theme for the past few decades in dengue vaccine development $[2,120]$. Although vaccine efficacy trials are under way, cumulative results indicate that there are concerns in particular safety issues- one being the possible immune-mediated enhancement scenario [43]. The other concern relates to the imbalance of immune responses to all serotypes [121].

\section{Challenge and Confrontation Issues}

\subsection{Pros and Cons of Evaluating Disease Parameters}

The dynamic nature of dengue clinical presentations makes the disease one of the most difficult vector-borne human diseases to be accurately diagnosed by doctors. Dengue is transmitted by the bite of mosquitoes carrying infectious dengue virus and is an acute disease. Patients do not normally recall when they were bitten but are often aware of how many days of fever he/she has experienced before seeking professional help from the clinics or hospitals. At that time, samples are taken and parameters are analyzed. Consequently, the conclusions drawn from these reports often conflict with each other, leading to debates over the clinical findings $[50,55,122]$. As a whole, reports from these clinical settings suggest that multiple factors are associated with disease development. These factors have been reviewed extensively [2,5,37] and will not be discussed in the current article. Instead, some of the underappreciated parameters are further discussed.

\subsection{Antibody Status in Acute Dengue Patients}

It is a well-established fact that antibodies play an important role in controlling infections from various pathogens. Hence, the humoral immune response is one of the critical indexes for the evaluation of vaccine efficacy. Dengue vaccine is not an exception. Unfortunately, due to its complicated viral biology in conjunction with the potential interference in antibody production between different serotypes, a consensus on the value of a neutralizing antibody response in dengue virus infections has not been reached $[64,81,123]$. The discrepancy may result from the fact that dengue is a timing disease; the lapse in time from the mosquito bite to the onset of the symptoms and the clinical presentation varies among infected individuals may dictate the outcomes of the disease and the analytic profiles [46]. One of the interesting observations found in dengue endemic countries, such as Thailand and Vietnam, is that the prevalence of dengue antibody in the general population, including school age children, can reach $90 \%-100 \%[124,125]$. This suggests that the majority of people in dengue endemic regions have likely encountered this pathogen two or even multiple times. According to the dogma on the immune response, anamnestic responses should occur within $1-3$ days after re-encountering the similar antigen (Figure 4). However, low levels of antibodies are observed from patient samples collected early on in infection, especially during the first couple of days after the onset of fever [45]. Our study with a cohort demonstrated a similar compatible trend (Figure 5). Although formation of immune complexes have been thought to cause the phenomenon, systematic investigations suggest that the peak of the immune-complex formation likely occurs along with the rising of the detectable antibody, which is 5 to 6 days after the onset of the fever or during the defervescence stage $[70,126,127]$. Thus, the profile of the immune response in dengue viral re-infection is unknown (Figure 6). There are many questions to be asked; such as why do the preexisting antibodies disappear upon reinfection in acute dengue patients? Why are memory B cells so hard to detect during re-infection? Does a dengue viral antigen or a factor induced during the viral infection 


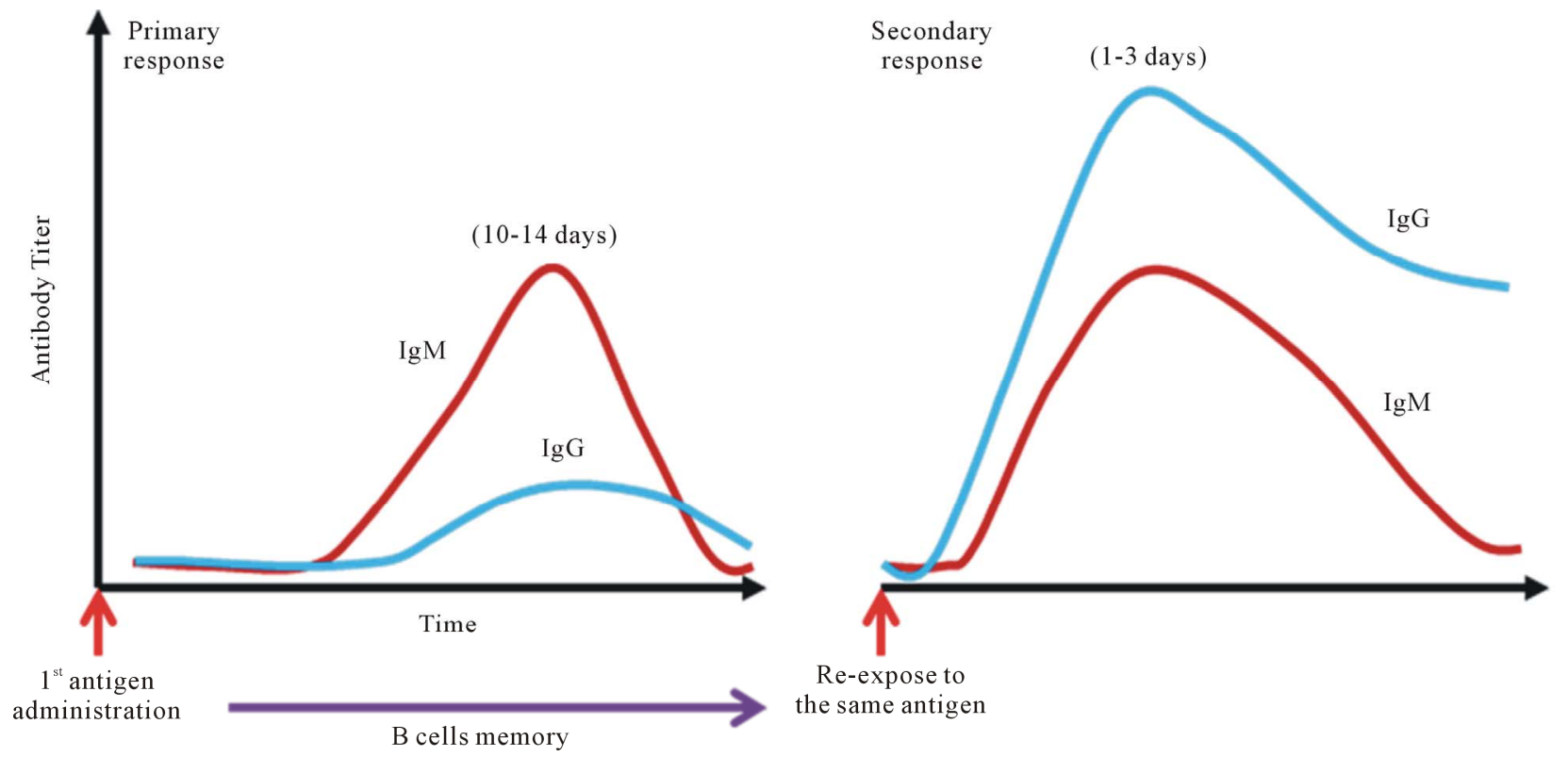

Figure 4. Dogma of anamnestic antibody response. The textbook knowledge, or the well-established belief of vaccinologists, is that upon administration of vaccine antigen to a naïve individual, antibodies to the antigen become detectable at about 10-14 days; IgM comes up first, followed by IgG. The scenario is called the primary response. Memory B cells become established along with the specific IgG. Upon re-exposed to the same antigen in the same host, production of the antibodies to the antigen is very rapid and robust, normally within 1 - 3 days after the injection. IgG is the first dominant antibody isotype, followed by IgM. This phenomenon is called the secondary response.

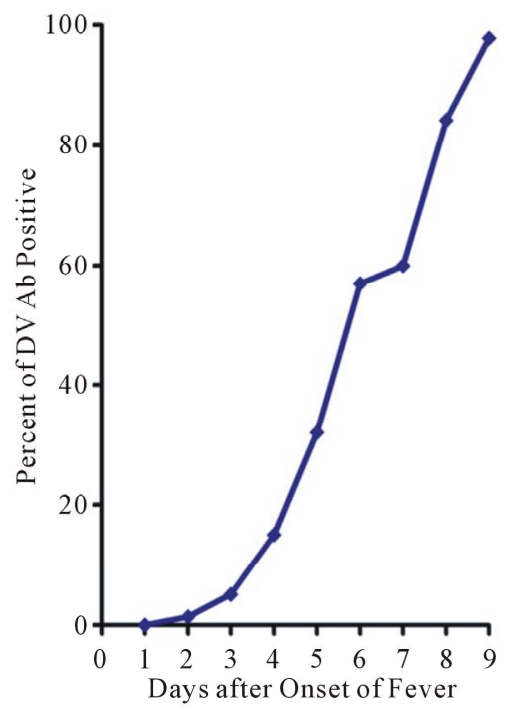

(a)

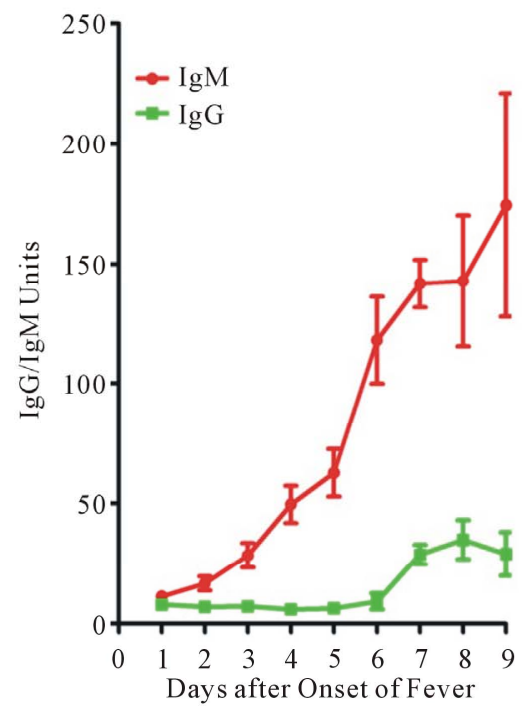

(b)

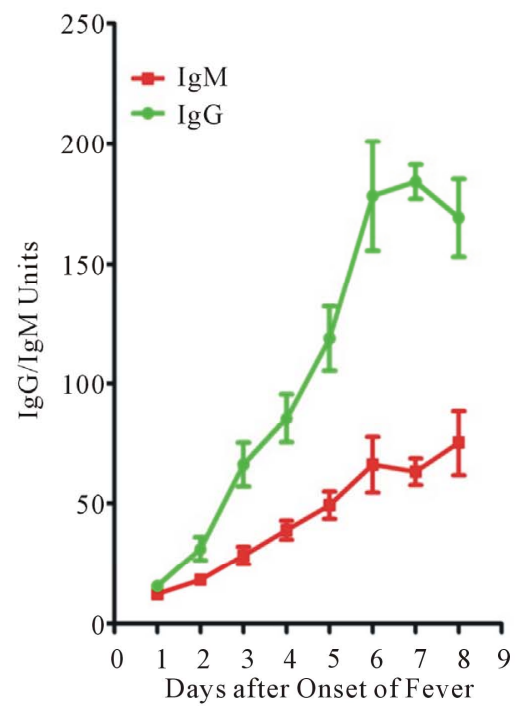

(c)

Figure 5. Antibody profiles in dengue patients. (a) Profile of dengue specific antibody in dengue patients. Serum specific antibody to dengue viral antigen is measured with a commercial available kit. Results are accumulated from dengue subjects with different days of fever onset. To our surprise, low percentage of dengue specific antibody is detected in samples taken during the first few days. To further understand the observed scenario, daily samples were taken from a study cohort of patients hospitalized with confirmed dengue. The definition of the primary and secondary dengue virus infections was adapted according to the WHO guidelines [15]; (b) Profile of primary dengue virus infection. A typical primary antibody response is observed in primary dengue patients; (c) Profile of secondary dengue virus infection. A low antibody titer, either IgG or IgM, is noticed in samples taken at the first few days of onset of fever, very similar to that of primary dengue virus infection. These samples were taken from patients known to have pre-existing dengue antibody. Patient samples are often taken very late in dengue virus infections. Hence, the abnormal secondary antibody response is a very unique feature of dengue pathogenesis. 


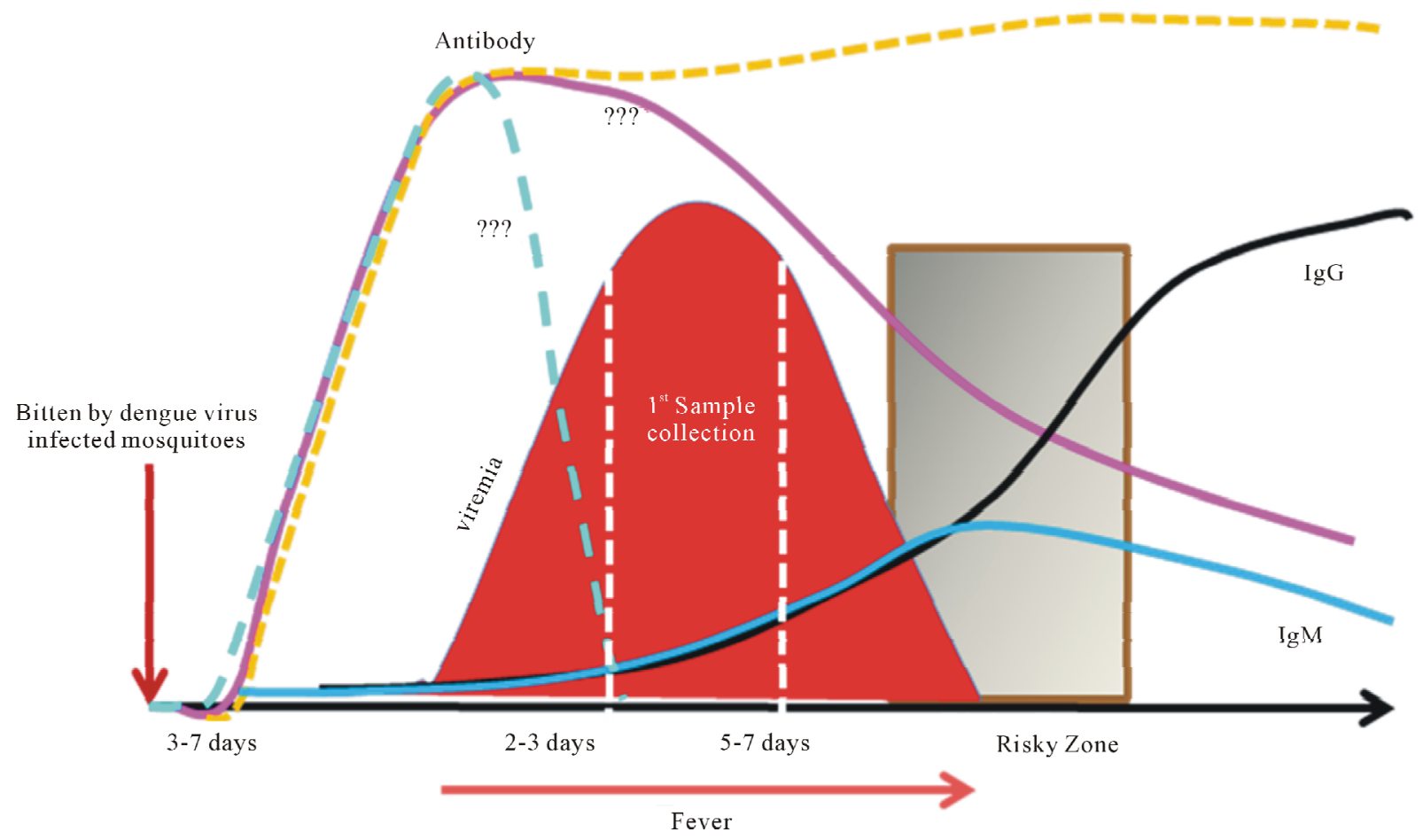

Figure 6. Status of antibody response in secondary dengue virus infected patient. Dengue patients often visit the clinic or hospital during the late stages of viral infection, resulting in samples being acquired from late time points. This figure shows the integration of the sequence of events pertinent to dengue disease development, including the lapse in time between virus inoculation by the mosquito and symptom onset, patient sampling, and the theorized vaccinology textbook on secondary antibody response. Patient samples are taken after the typical specific secondary antibody titer peaks. However, the status of the antibody response in natural dengue virus re-infected patients appears to deviate from the general dogma. Therefore, the fate of the pre-existing antibody and the status and functionality of the memory B cell population is unclear. Questions need to be urgently answered in order to provide a better and safer dengue vaccine. For example, are dengue specific antibodies produced during the incubation period and then rapidly decomposed by viral products or by other virally induced factors?

account for this phenomenon? Nevertheless, the mystery of the low antibody levels observed in dengue patients suffering re-infection has not been addressed and investigated well. In order to improve accuracy in predicting and evaluating the performance of dengue vaccine in vaccinees, this critical area warrants further study. Answers to these questions would definitely improve dengue vaccine design and efficacy.

\subsection{Antibody Producing Cells- - The Plasma Cells}

Despite the well-known fact on the importance of antibody in control of viral infections, very little information is available on the plasma cells, also called effector B cells, the antibody producing cells, in dengue patients. A review of the literature reveals conflicting information on the interaction of dengue virus with plasma cells or B cells in dengue patients and in dengue pathogenesis. Some reports advocate that B cells or plasma cells are permissive for dengue virus infection in vitro $[29,48$,
128-132], while others do not observe this feature [133, 134]. A few reports with samples taken from acute dengue patients suggest that viral antigens are associated with B-lymphocytes and that virus may replicate in these cells, a phenomenon that could explain the presence of atypical lymphocytes [135-137]. Another report indicates that a suppressor or inhibitor derived from dengue virus infection may contribute to the dysfunction of the B cells [138]. Furthermore, a few reports suggest that dengue virus induces autoantibodies, which cause lysis of B cells $[48,139,140]$. As a whole, evidence appears to suggest that an intimate relationship between dengue virus and $\mathrm{B}$ cells may exist. Nevertheless, an urgent need for more research on the role of B cells or plasma cells in the dengue virus life cycle is essential in order to comprehensively understand dengue pathogenesis and develop a better vaccine.

\subsection{Molecular Mimicry}

A properly functioning immune response to invaders or 
non-self substances is the result of the orchestration of a sophisticated network of signaling events coordinated by the immune system, which must balance these elements to prevent harm to the host. However, under certain conditions, the immune system can go amiss and attack its own components. Generally speaking, when an intruder's components display molecular or structural similarity or are identical to its host, antibodies raised against these antigens can induce harmful consequences to the host. The immune system is constantly being challenged by infection. The intimate relationships between infectious agents and autoimmunity have been well-established. Thousands of infectious agents have been identified and numerous components within these pathogens mimic their hosts [71,72,141-146]. The components of dengue virus are not an exception; broadly cross-reactive antibodies to the viral antigens have been shown to react with a variety of host proteins [71,72,144-146]. However, exactly how these self reactive antibodies are generated in dengue virus infection remains to be further elaborated.

In the event of dengue virus infection, molecular mimicry has been implicated to contribute to dengue pathogenesis [144,145]. Conformational mimicry between proteins from platelets, endothelial cells, and coagulatory factors with those from dengue virus may explain the cross-reactive properties of anti-NS1, anti-prM, or anti-E antibody, which may participate in disease development $[145,147]$. Although the wide spectrum of dengue virus epitopes that exploit molecular mimicry have been investigated in great detail $[144,146]$, the direct evidence that these peptides elicit cross-reactive $\mathrm{T}$ or $\mathrm{B}$ cell responses has not been provided. Thus more research needs to be done especially on this topic. Many questions abound, such as do the dengue virus-induced memory B or T cells provide agonists, antagonists or altered peptide ligands that can activate, block, or modulate effector functions? Do the avidities to the host protein and the viral mimicking epitope differ? Do pre-existing subclinical conditions make the activated memory $\mathrm{B}$ or $\mathrm{T}$ cells much easier to be aggravated upon re-infection with dengue virus? The actual incidence of autoimmune complications due to molecular mimicry in dengue patient is unknown and warrants further investigation. Nevertheless, the molecular mimicry observed in dengue virus infection should be considered an integral component to evaluating dengue vaccine safety.

\subsection{Autoantibody-Associated Macrophage Activation}

Macrophages are one of the most important players in innate defense within the network of the immune system. They are bestowed with a dynamic set of mechanisms that are powerful at combating many types of pathogens under activated conditions. There are many subtypes of activated macrophages and each has its unique effector functions in dealing with infectious agents [148-157]. Considering the complexity of the operational immune system, all classes of activated macrophages are likely to be present in samples taken from infected individuals. However, the differential and proportional distribution of these subpopulations of activated macrophages during dengue virus infection has not yet been well-documented.

Dengue virus-induced disease has its unique features. One of the hallmarks of DHF/DSS is an acute vascular permeability syndrome accompanied by abnormalities in hemostasis. Although the underlying mechanisms in the development of this disease are unresolved, immunopathogenesis is thought to be a major factor $[5,37,60]$. However, DHF/DSS develops very rapidly, usually over a period of hours, and resolves within 1 to 2 days in patients who receive appropriate fluid resuscitation. No discernible sequelae are usually found. Therefore, an alternative scenario must exist. We have reported that dengue virus infection causes intense immune activation. Aberrant immune responses such as cytokine overproduction and generation of autoantibody acting against platelets and endothelial cells occur after dengue virus infection [71,145-147,158-160]. In addition, we have proposed that dengue virus can cause severe hemophagocytic syndrome [161,162]. In dengue patients, monocytes or macrophages could be activated by cytokines including IFN $\gamma$ and TNF, dengue virus-immune complexes, and other stimuli. One of the likely functions of the activated macrophages is to implement the phagocytosis of the autoantibody-coated platelets and endothelial cells and thus contribute to the destruction of these uninfected cells. Anti-dengue antibodies become pathogenic and can enhance the dengue disease severity. The anti-NS1, anti-prM, and anti-E cross-reactive antibody action against platelets, endothelial cells, and coagulatory molecules provides an explanation for the targeted specificity and unique features of thrombocytopenia and plasma leakage observed during the development of DHF/DSS. We believe that this theory can explain the mechanistic steps of immunopathogenesis, and account for the specific characteristics of clinical, pathologic, and epidemiological observations that are unique in dengue virus-induced disease.

The autoantibody-associated macrophage activation has participated in many viral diseases [163]. Once it has been identified which subpopulation of activated macrophages is the key factor for progression to DHF/DSS post dengue virus infection, the current thoughts need to be re-scrutinized. Due to the molecular mimicry between 
dengue virus antigen and platelet or endothelial cell self antigens, the use of a live attenuated dengue vaccine could be considered problematic [43] and the safety of the vaccine currently under development could come into question [2]. The induction of autoimmunity after any attenuated dengue virus immunization would cause great concern in the future. Will a more severe disease be induced by subsequent dengue virus infections in vaccinated individuals because of the established memory of autoimmunity?

\subsection{Cooperative with Platelets}

The best known classical role of platelets is its importance as primary mediators of hemostasis, mainly in cooperation with other inflammatory processes. Cumulative information from the research has revealed an expansion of roles for platelets in unexpected areas, including a significant contribution in shaping and sharpening immune responses [164-168]. Recently, platelet expression of immunologically-related molecules that functionally modulate innate and adaptive immunity has been demonstrated [169-175]. One of the key aspects of platelets is their capability to bind leukocytes, especially monocytes, upon activation [176-178]. For example, platelet adhesive interactions with leukocytes and endothelial cells via P-selectin can lead to several pro-inflammatory events, including leukocyte rolling and activation, production of cytokine cascades, and recruitment of leukocytes to sites of tissue damage. Upon activation, platelets express on their surface CD154 protein that can induce the maturation of dendritic cells and regulate the adaptive immune response by stimulating T- and B-cell growth [172]. Furthermore, CD154 derived from platelets can influence $\mathrm{B}$ cell antibody production and their depletion may result in the decreased availability of antigen-specific antibody. The accumulated evidence thus far lends support to the concept that the CD154 molecule released from activated platelets enhances antigen presentation, improves CD8 T cell responses, and plays a critical functional role in normal T-dependent humoral immunity.

Obviously, other releasates from activated platelets are also present in the circulation of peripheral blood of dengue patients. Some of these factors may also be harmful to the host immune cells as well. One such molecule is polyphosphate (polyP), an inorganic, linear polymer of 60 - 100 phosphate residues linked by phosphoanhydride bonds [179]. PolyP functions in a basic metabolism as an alternate energy source in stress responses and as a structural component in prokaryotes and lower eukaryotes $[179,180]$. Human platelets contain high concentrations of polyP in their granules [181,182]. Synthetic polyP can selectively induce apoptosis in plasma cells in addition to other hemostatic functions
[183-185]. The cause of thrombocytopenia can be due to direct engagement of dengue virus with platelets [186, 187], which leads to their activation and release of byproducts, such as polyP. This evidence suggests that the current paradigm for the B cell germinal center response should be modified to include for the actions of platelets. Although much research is needed to solidify the relationship between plasma cells and polyP releasate from activated platelets, we advocate that polyP or other related molecules may be involved in dengue pathogenesis by altering the quality and/or quantity of antibody produced from plasma cells in dengue patients, and perhaps affects the overall immunity. Therefore, research on the cooperation and integration of platelets as a part of evaluation index in the dengue vaccine development profile is urgently needed.

\section{Perspective of Ideal Dengue Vaccines}

\subsection{General}

Although multiple and diversified approaches to dengue vaccine development are in the pipeline at different stages of clinical trials, others are still under preclinical development. Challenges that have to be faced include but are not limited to reducing dynamic reactogenicity with a balanced and lasting immune response against all four dengue virus serotypes (the type of immunity that confers protection in natural infections), mitigating the potential immune-enhanced and autoimmune-mediated diseases, and development of a suitable animal model to evaluate candidate vaccines. Nevertheless, further understanding the factors that contribute to the dengue pathogenesis could diffuse some of the challenges and the concerns. Some essential points on future dengue vaccine developments are suggested.

\subsection{Balancing Reactogenicity and Immunity}

The double-edged relationship between reactogenicity and immunity is a very intriguing topic in dengue virus infection [188]. High reactogenicity may result in a good immune response in some vaccine recipients but may cause severe outcomes in others. Low or poor reactogenicity may induce insufficient immunity in test subjects. There are four serotypes of dengue virus, and each of them can induce severe dengue disease. Reports in the literature suggest that the general immune responses that develop from the primary dengue infection provide a transient period of protection, $\sim 2$ to 6 months, from secondary encounters with any dengue viral serotype. However the antibodies elicited from this infection offer a life-long protection only from viruses of the same serotype $[77,81,189]$. This lends support to the important theme that antibodies play a protective role in dengue 
virus infections and that measuring the magnitude of the antibody response to the vaccine candidates is a critical index corresponding to disease prevention. Even though homotypic infection can generate life-long protective immunity, the protective immune parameters can wane over time, potentiating a severe consequence from a secondary dengue virus infection $[43,62,190]$. But the identity of these immune system members and the quantities needed for protection is currently unknown and remains a major challenge.

Furthermore, the assays currently available to measure neutralizing antibodies are not suitable to identify the true protective homotypic antibody and cannot differentiate between type specific, heterotypic and cross-reactive antibodies [44,64,191,192]. This may be critically important in dengue endemic regions where the majority of populations already have pre-existing dengue antibodies to at least one dengue viral serotype, but the levels of neutralizing antibodies to each serotype are unknown. Therefore, one could envision that the enhanced vaccine reactogenicity may be a health threat when live attenuated tetravalent vaccine is administered to individuals from endemic countries with partial immunity. The results obtained from endemic regions demonstrate that the levels of pre-existing neutralizing antibodies against the infecting virus are not associated with viremia levels in secondary infection [65]. This concept may explain the recent report on monovalent attenuated DENV1rDEN1$\Delta 30$ vaccine; despite its high immunogenicity, ability to elicit a strong neutralizing antibody titer, a significant rise was not observed after the second dose of the vaccine, independent of the dosing interval [193]. Consequently, measurement of the elicited neutralizing antibodies may not be a valuable index to assess the success of a dengue vaccine. It is therefore anticipated that tetravalent seroconversion with adequate $\mathrm{T}$ cell immunity, especially CD8+ memory, responses should be included in as part of the efficacy index in order to preclude enhanced disease even many years following vaccination. Obviously, the ideal dengue attenuated vaccine should be capable of diminishing deleterious effects including immune evasion and generating host responses that potentiate protective immunity. The right viral compositions of the dengue tetravalent attenuated vaccine that can provide the proper balance between reactogenicity and immunity is a very difficult task to achieve and remains the biggest challenge to the dengue vaccine development strategy currently in place.

\subsection{Mitigating Autoimmunity Risk}

As aforementioned, why the majority of antibodies to dengue viral antigens are cross-reactive in nature, including to host proteins, remains a mystery. These anti- bodies may be beneficial, cross protecting the host from other flaviviruses, but are also likely harmful to the affected individual $[194,195]$. These unwanted cross-reactive antibodies could lead to some very serious situations-one dire consequence being death $[63,196]$. Some devastating effects have been documented, including autoantibody conjugating with circulating materials or inducing the release of deleterious substances from cells lined-up on the surface of capillaries; these events have the capacity to trigger hemorrhage and/or plasma leakage in dengue patients $[72,73,145,147,197,198]$. Currently, the magnitude of the potential side effects resulting from these autoantibodies, formed due to mimicry, has not been centered in the agenda of the current dengue vaccine developers. Hence, these potential adverse reactions have not been integrated as part of the efficacy evaluation index in tetravalent attenuated dengue vaccine clinical trials. Although investigations on the epitopes that can cause cross-reactive $\mathrm{T}$ or $\mathrm{B}$ cell responses has not been initiated, the molecular details of these protein sequences from viral antigens that elicit autoantibody production have been investigated very well [144,146, 199,200]. A strategy can be applied, such as modifying the coding sequence of the dengue viral genomes and altering these epitopes in the integrated virus strains to mitigate the potential side effects and enhance the safety profile of the dengue vaccines.

\subsection{Enhancing the Effector Antibody-Producing Plasma Cells}

The importance of B cells, especially those constitutively producing antibody that control invading pathogens upon re-infection, has been well-established in vaccine regimens. However, antibody titers are low in patients who suffer from acute dengue in spite of high levels of pre-existing dengue specific antibodies. Also a paucity of detectable memory $B$ cells in these patients during acute illness have been observed [76]. Although the probable factors or mechanisms leading to the dysfunction or disappearance of antibody-producing plasma cells in dengue patients at acute illness are unclear for the time being, one of the strategies to improve the dengue vaccine efficacy would be increased survival of memory B or plasma cells. One of the likely clues to sustain and/or enhance the survival of the B cells in dengue patients may be extracted from one scarce report on concurrent malaria and dengue virus infections, which rarely occurs in spite of the high prevalence of both these pathogens in tropical and subtropical temporal zones [201]. Interestingly, it has been shown that the cysteine-rich interdomain region $1 \alpha$ (CIDR $1 \alpha$ ) of the Plasmodium falciparum erythrocyte membrane protein 1 can protect and rescue B cells from apoptosis and increase the proportion of cycling cells 
[202]. Pilot investigations indicate that apoptosis seems to be one of the likely causes to account for the low levels of plasma cells in acute dengue patients (personal observation). Although scientifically, the CIDR $1 \alpha$ playing a role in malaria-dengue co-infections in endemic regions remains to be elucidated, this concept warrants further investigation. Potentially CIDR $1 \alpha$ could be coadministered with attenuated dengue vaccine to improve plasma cell survival and function.

\section{Summary and Conclusions}

Dengue has become one of the most important mosquito-borne human diseases globally. Several measures have been applied and utilized to attempt to slow down or reduce the spread and the burden of the disease, but to no avail. Dengue seems to be a preventable disease considering the success achieved in vaccine design with other flaviviruses, such as yellow fever. Hence, a dengue vaccine appears to be an attainable effective method to control and prevent the spread of the dengue virus. With this notion, numerous dengue vaccines have been designed with a variety of approaches. Several of these dengue vaccines are currently going through clinical trials and some are still in pre-clinical development. Importantly, some of these dengue vaccines could be licensed within the next few years if all goes as planned [203]. However, the actual safety and population-based efficacy of these vaccines remain unknown. The clinical endpoints that define dengue vaccine safety and efficacy may need to be updated. Other parameters related to the safety of dengue vaccines are underappreciated by dengue vaccine developers, public health sectors, and policy makers and regulators. These factors play a part and are relevant in the complex disease manifestations seen in dengue patients. Integration of these factors into the current vaccine design platform, which has eluded the development of a safe and effective dengue vaccine for years, could finally put a viable candidate within reach.

\section{Acknowledgements}

We would like to thank the clinical staffs at the Division of Infectious Diseases in the Department of Pediatrics at the Siriraj Hospital, Mahidol University, Bangkok, Thailand. This study was supported by Emory SOM start-up fund (GCP) and Grants \# NSC99-2321-B006-008 (HYL and YSL) from the National Science Council, Taiwan.

\section{REFERENCES}

[1] D. J. Gubler, "Dengue and Dengue Hemorrhagic Fever," Clinical Microbiology Reviews, Vol. 11, No. 3, 1998, pp. 480-496.

[2] B. R. Murphy and S. S. Whitehead, "Immune Response to Dengue Virus and Prospects for a Vaccine," Annual Review of Immunology, Vol. 29, 2011, pp. 587-619. doi:10.1146/annurev-immunol-031210-101315

[3] S. J. Thomas and T. P. Endy, "Vaccines for the Prevention of Dengue: Development Update," Human Vaccines, Vol. 7, No. 6, 2011, pp. 674-684.

doi: $10.4161 /$ hv.7.6.14985

[4] D. P. Webster, J. Farrar and S. Rowland-Jones, "Progress towards a Dengue Vaccine," Lancet Infectious Diseases, Vol. 9, No. 11, 2009, pp. 678-687. doi:10.1016/S1473-3099(09)70254-3

[5] A. L. Rothman, "Immunity to Dengue Virus: A Tale of Original Antigenic Sin and Tropical Cytokine Storms," Nature Review Immunology, Vol. 11, No. 8, 2011, pp. 532-543. doi: $10.1038 /$ nri30142011

[6] J. Schmitz, J. Roehrig, A. Barrett and J. Hombach, "Next Generation Dengue Vaccines: A Review of Candidates in Preclinical Development," Vaccine, Vol. 29, No. 42, 2011, pp. 7276-7284. doi:10.1016/j.vaccine.2011.07.017

[7] S. Swaminathan, G. Batra and N. Khanna, "Dengue Vaccines: State of the Art," Expert Opinion on Therapy Patents, Vol. 20, No. 6, 2010, pp. 819-835. doi: $10.1517 / 13543771003767476$

[8] M. G. Gusman, "Dengue Vaccines: New Developments," Drugs Future, Vol. 36, 2011, pp. 45-62.

[9] WHO, "Dengue," World Health Organization, 2004.

[10] A. A. Hoffmann, B. L. Montgomery, J. Popovici, I. Iturbe-Ormaetxe, P. H. Johnson, F. Muzzi, et al., "Successful Establishment of Wolbachia in Aedes Populations to Suppress Dengue Transmission," Nature, Vol. 476, No. 7361, 2011, pp. 454-457. doi:10.1038/nature10356

[11] T. Walker, P. H. Johnson, L. A. Moreira, I. Iturbe-Ormaetxe, F. D. Frentiu, C. J. McMeniman, et al., "The wMel Wolbachia Strain Blocks Dengue and Invades Caged Aedes Aegypti Populations," Nature, Vol. 476, No. 7361, 2011, pp. 450-453. doi:10.1038/nature 10355

[12] K. B. Anderson, S. Chunsuttiwat, A. Nisalak, M. P. Mammen, D. H. Libraty, A. L. Rothman, et al., "Burden of Symptomatic Dengue Infection in Children at Primary School in Thailand: A Prospective Study," Lancet, Vol. 369, No. 9571, 2007, pp. 1452-1459. doi:10.1016/S0140-6736(07)60671-0

[13] D. J. Gubler, "Epidemic Dengue/Dengue Hemorrhagic Fever as a Public Health, Social and Economic Problem in the 21st Century," Trends in Microbiology, Vol. 10, No. 2, 2002, pp. 100-103.

[14] J. A. Suaya, D. S. Shepard, J. B. Siqueira, C. T. Martelli, L. C. Lum, L. H. Tan, et al., "Cost of Dengue Cases in Eight Countries in the Americas and Asia: A Prospective Study," The American Journal of Tropical Medicine and Hygiene, Vol. 80, No. 5, 2009, pp. 846-855.

[15] WHO, "Dengue Guidelines for Diagnosis, Treatment, Prevention and Control," Geneva, World Health Organization, 2009.

http://whqlibdoc.who.int/publications/2009/97892415478 71_eng.pdf 
[16] WHO, "Dengue Haemorrhagic Fever: Diagnosis, Treatment, Prevention and Control," 2nd Edition, World Health Organization, Geneva, 1997.

[17] J. G. Rigau-Perez, G. G. Clark, D. J. Gubler, P. Reiter, E. J. Sanders and A. V. Vorndam, "Dengue and Dengue Haemorrhagic Fever," Lancet, Vol. 352, No. 9132, 1998, pp. 971-977.

[18] J. Barniol, R. Gaczkowski, E. V. Barbato, R. V. da Cunha, D. Salgado, E. Martinez, et al., "Usefulness and Applicability of the Revised Dengue Case Classification by Disease: Multi-Centre Study in 18 Countries," BMC Infectious Diseases, Vol. 11, 2011, p. 106. doi:10.1186/1471-2334-11-106

[19] P. S. Basuki, Budiyanto, D. Puspitasari, D. Husada, W. Darmowandowo, Ismoedijanto, et al., "Application of Revised Dengue Classification Criteria as a Severity Marker of Dengue Viral Infection in Indonesia," Southeast Asian Journal of Tropical Medicine and Public Health, Vol. 41, No. 5, 2010, pp. 1088-1094.

[20] R. W. Boulton and E. G. Westaway, "Comparisons of Togaviruses: Sindbis Virus (Group A) and Kunjin Virus (Group B)," Virology, Vol. 49, No. 1, 1972, pp. 283-289.

[21] G. R. Cleaves and D. T. Dubin, "Methylation Status of Intracellular Dengue Type 240 S RNA," Virology, Vol. 96, No. 1, 1979, pp. 159-165. doi:10.1016/0042-6822(79)90181-8

[22] G. Wengler and H. J. Gross, "Studies on Virus-Specific Nucleic Acids Synthesized in Vertebrate and Mosquito Cells Infected with Flaviviruses," Virology, Vol. 89, No. 2, 1978, pp. 423-437. doi:10.1016/0042-6822(78)90185-X

[23] G. W. Smith and P. J. Wright, "Synthesis of Proteins and Glycoproteins in Dengue Type 2 Virus-Infected Vero and Aedes Albopictus Cells," Journal of General Virology, Vol. 66, No. 3, 1985, pp. 559-571. doi:10.1099/0022-1317-66-3-559

[24] S. A. Stohlman, C. L. Wisseman, O. R. Eylar Jr. and D. J. Silverman, "Dengue Virus-Induced Modifications of Host Cell Membranes," Journal of Virology, Vol. 16, No. 4, 1975, pp. 1017-1026.

[25] D. J. Gubler and G. Kuno, "Dengue and Dengue Hemorrhagic Fever," CABI, Wallingford, 1997.

[26] R. Perera and R. J. Kuhn, "Structural Proteomics of Dengue Virus," Current Opinion in Microbiology, Vol. 11, No. 4, 2008, pp. 369-377. doi:10.1016/j.mib.2008.06.004

[27] D. W. C. Beasley and A. D. Barrett, "The Infectious Agent," In: S. B. Halstead, Ed., Dengue, Imperial College Press, London, 2008, pp. 29-73.

[28] S. Sriurairatna and N. Bhamarapravati, "Replication of Dengue-2 Virus in Aedes Albopictus Mosquitoes. An Electron Microscopic Study," The American Journal of Tropical Medicine and Hygiene, Vol. 26, No. 6, 1977, pp. 1199-1205.

[29] S. Sriurairatna, N. Bhamarapravati, A. R. Diwan and S. B. Halstead, "Ultrastructural Studies on Dengue Virus Infection of Human Lymphoblasts," Infection and Immunity,
Vol. 20, No. 1, 1978, pp. 173-179.

[30] J. R. Paul, J. L. Melnick and A. B. Sabin, "Experimental Attempts to Transmit Phlebotomus and Dengue Fevers to Chimpanzees," Proceedings of the Society Experimental Biology and Medicine, Vol. 68, No.1, 1948, pp. 193-198. doi:10.3181/00379727-68-16431

[31] R. J. Kuhn, W. Zhang, M. G. Rossmann, S. V. Pletnev, J. Corver, E. Lenches, et al., "Structure of Dengue Virus: Implications for Flavivirus Organization, Maturation, and Fusion," Cell, Vol. 1108, No. 5, 2002, pp. 717-725. doi:10.1016/S0092-8674(02)00660-8

[32] Y. Zhang, J. Corver, P. R. Chipman, W. Zhang, S. V. Pletnev, D. Sedlak, et al., "Structures of Immature Flavivirus Particles," The EMBO Journal, Vol. 22, No. 11, 2003, pp. 2604-2613. doi:10.1093/emboj/cdg270

[33] T. M. Stevens and R. W. Schlesinger, "Studies on the Nature of Dengue Viruses. I. Correlation of Particle Density, Infectivity, and RNA Content of Type 2 Virus," Virology, Vol. 27, No.1, 1965, pp. 103-112. doi:10.1016/0042-6822(65)90147-9

[34] T. J. Smith, W. E. Brandt, J. L. Swanson, J. M. McCown and E. L. Buescher, "Physical and Biological Properties of Dengue-2 Virus and Associated Antigens," Journal of Virology, Vol. 5, No.4, 1970, pp. 524-532.

[35] J. Junjhon, M. Lausumpao, S. Supasa, S. Noisakran, A. Songjaeng, P. Saraithong, et al., "Differential Modulation of prM Cleavage, Extracellular Particle Distribution, and Virus Infectivity by Conserved Residues at Nonfurin Consensus Positions of the Dengue Virus pr-M Junction," Journal of Virology, Vol. 82, No. 21, 2008, pp. 1077610791. doi:10.1128/JVI.01180-08

[36] F. Masciopinto, C. Giovani, S. Campagnoli, L. GalliStampino, P. Colombatto, M. Brunetto, et al., "Association of Hepatitis C Virus Envelope Proteins with Exosomes," European Journal of Immunology, Vol. 34. No. 10, 2004, pp. 2834-2842. doi:10.1002/eji.200434887

[37] S. B. Halstead, "Dengue," Lancet, Vol. 370, No. 9599, 2007, pp. 1644-1652. doi:10.1016/S0140-6736(07)61687-0

[38] E. C. Holmes and S. S. Burch, "The Causes and Consequences of Genetic Variation in Dengue Virus," Trends in Microbiology, Vol. 8, No. 2, 2000, pp. 74-77. doi:10.1016/S0966-842X(99)01669-8

[39] T. P. Monath, J. Arroyo, I. Levenbook, Z. X. Zhang, J. Catalan, K. Draper, et al., "Single Mutation in the Flavivirus Envelope Protein Hinge Region Increases Neurovirulence for Mice and Monkeys but Decreases Viscerotropism for Monkeys: Relevance to Development and Safety Testing of Live, Attenuated Vaccines," Journal of Virology, Vol. 76, No. 4, 2002, pp. 1932-1943. doi:10.1128/JVI.76.4.1932-1943.2002

[40] D. J. Gubler, "Dengue and Dengue Hemorrhagic Fever," Clinical Microbiology Reviews, Vol. 11, No. 3, 1998, pp. 480-496. doi:10.1016/S0140-6736(97)12483-7

[41] R. Rico-Hesse, "Dengue Virus Markers of Virulence and Pathogenicity," Future Virology, Vol. 4, No. 6, 2009, pp. 
581-594. doi:10.2217/fvl.09.51

[42] K. C. Leitmeyer, D. W. Vaughn, D. M. Watts, R. Salas, I. Villalobos, de Chacon, et al., "Dengue Virus Structural Differences That Correlate with Pathogenesis," Journal of Virology, Vol. 73, No.6, 1999, pp. 4738-4747.

[43] E. R. Moxon and C. A. Siegrist, "The Next Decade of Vaccines: Societal and Scientific Challenges," Lancet, Vol. 378, No. 9788, 2011, pp. 348-359. doi:10.1016/S0140-6736(11)60407-8

[44] M. G. Guzman, S. B. Halstead, H. Artsob, P. Buchy, J. Farrar, D. J. Gubler, et al., "Dengue: A Continuing Global Threat," Nature Review Microbiology, Vol. 8, No. 12, 2010, pp. S7016. doi:10.1038/nrmicro2460

[45] D. W. Vaughn, S. Green, S. Kalayanarooj, B. L. Innis, S. Nimmannitya, S. Suntayakorn, et al., "Dengue in the Early Febrile Phase: Viremia and Antibody Responses," Journal of Infectious Diseases, Vol. 176, No. 2, 1997, pp. 322-330. doi:10.1086/514048

[46] J. S. Simmons, J. H. St. John and F. H. K. Reynolds, "Experimental Studies of Dengue," Philippine Journal of Science, Vol. 44, 1932, pp. 1-251.

[47] J. F. Siler, M. W. Hall and A. P. Hitchins, "Dengue: Its History, Epidemiology, Mechanism of Transmission, Etiology, Clinical Manifestations, Immunity and Prevention," Philippine Journal of Science, Vol. 29, 1926, pp. $1-340$.

[48] I. Kurane, U. Kontny, J. Janus and F. A. Ennis, "Dengue-2 Virus Infection of Human Mononuclear Cell Lines and Establishment of Persistent Infections," Archives of Virology, Vol. 110, No. 1-2, 1990, pp. 91-101. doi:10.1007/BF01310705

[49] S. Yoksan and N. Bhamarapravati, "Localization of Dengue Antigens in Tissue Specimens from Fatal Cases of Dengue Hemorrhagic Fever," In: T. Pang and R. Pathmanathan, Eds., Proceedings of the International Conference on Dengue/Dengue Hemorrhagic Fever, University of Malaya, Kuala Lumpur, 1983, pp. 406-410.

[50] L. Rosen and M. M. Khin, "Recovery of Virus from the Liver of Children with Fatal Dengue: Reflections on the Pathogenesis of the Disease and Its Possible Analogy with That of Yellow Fever," Research in Virology, Vol. 140, No. 4, 1989, pp. 351-360. doi:10.1016/S0923-2516(89)80115-3

[51] A. Nisalak, S. B. Halstead, P. Singharaj, S. Udomsakdi, S. W. Nye and K. Vinijchaikul, "Observations Related to Pathogenesis of Dengue Hemorrhagic Fever. 3. Virologic Studies of Fatal Disease," The Yale Journal of Biology and Medicine, Vol. 42, No. 5, 1970, pp. 293-310.

[52] K. Jessie, M. Y. Fong, S. Devi, S. K. Lam and K. T. Wong, "Localization of Dengue Virus in Naturally Infected Human Tissues, by Immunohistochemistry and in Situ hybridization," Journal of Infectious Diseases, Vol. 189, No. 8, 2004, pp. 1411-1418. doi:10.1086/383043

[53] S. B. Halstead, E. J. O'Rourke and A. C. Allison, "Dengue Viruses and Mononuclear Phagocytes. II. Identity of Blood and Tissue Leukocytes Supporting in Vitro Infection," Journal of Experimental Medicine, Vol. 146, No. 1,
1977, pp. 218-229.

[54] N. Bhamarapravati, "Pathology and Pahtogenesis of DHF. First ICMR Seminar on Dengue and Dengue Heomorrhagic Fever," Kobe University School of Medicine, Kobe, 1980, pp. 207-216.

[55] J. Farrar, "Clinical Features of Dengue," In: S. B. Halstead, Eds., Dengue, Imperial College Press, London, 2008, pp. 171-191.

[56] H. R. Bierman and E. R. Nelson, "Hematodepressive Virus Diseases of Thailand," Annals of Internal Medicine, Vol. 62, 1965, pp. 867-884.

[57] A. Dasaneyavaja and U. Charansri, "First Known Isolation of a Dengue Virus from Other Human Source than Blood. Symposium on Hemorrhagic Fever," SEATO Medical Research Monograph, Bangkok, 1961, p. 61.

[58] Y. C. Chan, K. A. Lim and B. C. Ho, "Recent Epidemics of Hemorrhagic Fever in Singapore," Japanese Journal of Medical Science \& Biology, Vol. 20, 1967, pp. 81-88.

[59] S. B. Halstead, “The Alexander D. Langmuir Lecture. The Pathogenesis of Dengue. Molecular Epidemiology in Infectious Disease," American Journal of Epidemiology, Vol. 114, No. 5, 1981, pp. 632-648.

[60] S. Green and A. Rothman, "Immunopathological Mechanisms in Dengue and Dengue Hemorrhagic Fever," Current Opinion in Infectious Diseases, Vol. 19, No. 5, 2006, pp. 429-436. doi:10.1097/01/qco.0000244047.31135.fa

[61] N. J. Marchette, S. B. Halstead, W. A. Falkler, A. Stenhouse Jr. and D. Nash, "Studies on the Pathogenesis of Dengue Infection in Monkeys. 3. Sequential Distribution of Virus in Primary and Heterologous Infections," Journal of Infectious Diseases, Vol. 128, No. 1, 1973, pp. 2330. doi:10.1093/infdis/128.1.23

[62] S. B. Halstead, "Epidemiological Studies of Thai Haemorrhagic Fever, 1962-64," Bulletin of World Health Organization, Vol. 35, No. 1, 1966, pp. 80-81.

[63] S. B. Halstead, "Pathogenesis of Dengue: Challenges to Molecular Biology," Science, Vol. 239, No. 4839, 1988, pp. 476-481.

[64] S. J. Thomas, A. Nisalak, K. B. Anderson, D. H. Libraty, S. Kalayanarooj, D. W. Vaughn, et al., "Dengue Plaque Reduction Neutralization Test (PRNT) in Primary and Secondary dengue Virus Infections: How Alterations in Assay Conditions Impact Performance," American Journal of Tropical Medicine and Hygiene, Vol. 81, No. 5, 2009, pp. 825-833. doi:10.4259/astmh.2009.08-0625

[65] T. P. Endy, A. Nisalak, S. Chunsuttitwat, D. W. Vaughn, S. Green, F. A. Ennis, et al., "Relationship of Preexisting Dengue Virus (DV) Neutralizing Antibody Levels to Viremia and Severity of Disease in a Prospective Cohort Study of DV Infection in Thailand," Journal of Infectious Diseases, Vol. 189, No. 6, 2004, pp. 990-1000.

[66] C. C. Lin, Y. H. Huang, P. Y. Shu, H. S. Wu, Y. S. Lin, T. M. Yeh, et al., "Characteristic of Dengue Disease in Taiwan: 2002-2007," American Journal of Tropical Medicine and Hygiene, Vol. 82, No. 4, 2010, pp. 731-739. doi:10.4269/astmh.2010.09-0549 
[67] A. Balmaseda, S. N. Hammond, L. Perez, Y. Tellez, S. I. Saborio, J. C. Mercado, et al., "Serotype-Specific Differences in Clinical Manifestations of Dengue," American Journal of Tropical Medicine Hygiene, Vol. 74, No. 3, 2006, pp. 449-456.

[68] E. Meltzer and E. Schwartz, "A Travel Medicine View of Dengue and Dengue Hemorrhagic Fever," Travel Medicine and Infectious Diseases, Vol. 7, No. 5, 2009, pp. 278-283. doi:10.1016/j.tmaid.2009.05.002

[69] D. H. Libraty, L. P. Acosta, V. Tallo, E. SegubreMercado, A. Bautista, J. A. Potts, et al., "A Prospective Nested Case-Control Study of Dengue in Infants: Rethinking and Refining the Antibody-Dependent Enhancement Dengue Hemorrhagic Fever Model," PLoS Medicine, Vol. 6, No. 10, 2009, p. e1000171. doi:10.1371/journal.pmed.1000171

[70] W. Ruangjirachuporn, S. Boonpucknavig and S. Nimmanitya, "Circulating Immune Complexes in Serum from Patients with Dengue Haemorrhagic Fever," Clinical and Experimental Immunology, Vol. 36, No. 1, 1979, pp. 4653.

[71] C. F. Lin, H. Y. Lei, C. C. Liu, H. S. Liu, T. M. Yeh, S. T. Wang, et al., "Generation of IgM Anti-Platelet Autoantibody in Dengue Patients," Journal of Medical Virology, Vol. 63, No. 2, 2001, pp. 143-149. doi:10.1002/1096-9071(20000201)63:2<143::AID-JMV1 009>3.0.CO;2-L

[72] K. Oishi, S. Inoue, M. T. Cinco, E. M. Dimaano, M. T. Alera, J. A. Alfon, et al., "Correlation between Increased Platelet-Associated IgG and Thrombocytopenia in Secondary Dengue Virus Infections," Journal of Medical Virology, Vol. 71, No. 2, 2003, pp. 259-264. doi:10.1002/jmv.10478

[73] M. Saito, K. Oishi, S. Inoue, E. M. Dimaano, M. T. Alera, A. M. Robles, et al., "Association of Increased Platelet-Associated Immunoglobulins with Thrombocytopenia and the Severity of Disease in Secondary Dengue Virus Infections," Clinical and Experimental Immunology, Vol. 138, No. 2, 2004, pp. 299-303. doi:10.1111/j.1365-2249.2004.02626.x

[74] S. Honda, M. Saito, E. M. Dimaano, P. A. Morales, M. T. Alonzo, L. A. Suarez, et al., "Increased Phagocytosis of Platelets from Patients with Secondary Dengue Virus Infection by Human Macrophages," American Journal of Tropical Medicine and Hygiene, Vol. 80, No. 5, 2009, pp. 841-845.

[75] R. W. Faint, "Platelet-Neutrophil Interactions: Their Significance," Blood Reviews, Vol. 6, No. 2, 1992, pp. 83-91. doi:10.1016/0268-960X(92)90010-N

[76] J. J. Tsai, Y. H. Jen, J. S. Chang, H. M. Hsiao, S. Noisakran and G. C. Perng, "Frequency Alterations in Key Innate Immune Cell Components in the Peripheral Blood of Dengue Patients Detected by FACS Analysis," Journal of Innate Immunity, Vol. 3, 2011, pp. 530-540. doi:10.1159/000322904

[77] WHO, "Dengue: Guidelines for Diagnosis, Treatment, Prevention and Control," World Health Organization, Geneva, 2009.
[78] J. B. Cleland, B. Bradley and W. Macdonald, "Further Experiments in the Etiology of Dengue Fever," Journal of Hygiene (London), Vol. 18, No. 3, 1919, pp. 217-254.

[79] IMR, "Dengue Fever Studies in Malaysia," The Institute for Medical Research, Kuala Lumpur, 1986.

[80] A. B. Sabin and R. W. Schlesinger, "Production of Immunity to Dengue with Virus Modified by Propagation in Mice," Science, Vol. 101, No. 2634, 1945, pp. 640-642.

[81] A. B. Sabin, "Research on Dengue during World War II," American Journal of Tropical Medicine and Hygiene, Vol. 1, 1952, pp. 30-50.

[82] R. Kimura and S. Hotta, "Studies on Dengue Fever (VI). On the Inoculation of Dengue Virus into Mice (in Japanese)," Nippom Igaku, Vol. 3379, 1944, pp. 629-633.

[83] S. Hotta, "Experimental Studies on Dengue I Isolation, Identification and Modification of the Virus," Journal of Infectious Diseases, Vol. 90, No. 1, 1952, pp. 1-9.

[84] L. E. Yauch and S. Shresta, "Mouse Models of Dengue Virus Infection and Disease," Antiviral Research, Vol. 80, No. 2, 2008, pp. 87-93. doi:10.1016/i.antiviral.2008.06.010

[85] M. C. Cassetti, A. Durbin, E. Harris, R. Rico-Hesse, J. Roehrig, A. Rothman, et al., "Report of an NIAID Workshop on Dengue Animal Models," Vaccine, Vol. 28, No. 26, 2010, pp. 4229-4234. doi:10.1016/j.vaccine.2010.04.045

[86] K. L. Williams, S. Zompi, P. R. Beatty and E. Harris, “A Mouse Model for Studying Dengue Virus Pathogenesis and Immune Response," Annals of New York Academic of Science, Vol. 1171, Suppl. 1, 2009, pp. E12-23. doi:10.1111/j.1749-6632.2009.05057.x

[87] R. M. Zellweger, T. R. Prestwood and S. Shresta, "Enhanced Infection of Liver Sinusoidal Endothelial Cells in a Mouse Model of Antibody-Induced Severe Dengue Disease," Cell Host and Microbe, Vol. 7, No. 2, 2010, pp. 128-139. doi:10.1016/j.chom.2010.01.004

[88] S. J. Balsitis, K. L. Williams, R. Lachica, D. Flores, J. L. Kyle, E. Mehlhop, et al., "Lethal Antibody Enhancement of Dengue Disease in Mice Is Prevented by Fc Modification," PLoS Pathogens, Vol. 6, No. 2, 2010, p. e1000790. doi:10.1371/journal.ppat.1000790

[89] D. A. Bente and R. Rico-Hesse, "Models of Dengue Virus Infection," Drug Discovery Today Disease Models, Vol. 3, No. 1, 2006, pp. 97-103. doi:10.1016/j.ddmod.2006.03.014

[90] J. Mota and R. Rico-Hesse, "Humanized Mice Show Clinical Signs of Dengue Fever According to Infecting Virus Genotype," Journal of Virology, Vol. 83, No. 17, 2009, pp. 8638-8645. doi:10.1128/JVI.00581-09

[91] J. Mota and R. Rico-Hesse, "Dengue Virus Tropism in Humanized Mice Recapitulates Human Dengue Fever," PLoS One, Vol. 6, No. 6, 2011, p. e20762. doi:10.1371/journal.pone.0020762

[92] J. G. Kuruvilla, R. M. Troyer, S. Devi and R. Akkina, "Dengue Virus Infection and Immune Response in $\mathrm{Hu}-$ manized RAG2(-/-)Gamma(c)(-/-) (RAG-hu) Mice," Vi- 
rology, Vol. 369, No. 1, 2007, pp. 143-152. doi:10.1016/j.virol.2007.06.005

[93] S. B. Halstead, H. Shotwell and J. Casals, "Studies on the Pathogenesis of Dengue Infection in Monkeys. I. Clinical Laboratory Responses to Primary Infection," Journal of Infectious Diseases, Vol. 128, No. 1, 1973, pp. 7-14. doi:10.1093/infdis/128.1.7

[94] D. W. Vaughn, S. Green, S. Kalayanarooj, B. L. Innis, S. Nimmannitya, S. Suntayakorn, et al., "Dengue Viremia Titer, Antibody Response Pattern, and Virus Serotype Correlate with Disease Severity," Journal of Infectious Diseases, Vol. 181, No. 1, 2000, pp. 2-9. doi:10.1086/315215

[95] N. Onlamoon, S. Noisakran, H. M. Hsiao, A. Duncan, F. Villinger, A. A. Ansari, et al., "Dengue Virus-Induced Hemorrhage in a Nonhuman Primate Model," Blood, Vol. 115, No. 9, 2010, pp. 1823-1834. doi:10.1182/blood-2009-09-242990

[96] G. Blanc and J. Caminopetros, "Contributions to the Study of Vaccination against Dengue," Bulletin of Academic Medicine, Vol. 102, No. 26, 1929, pp. 40-47.

[97] J. H. St. John and R. L. Holt, "A Dengue Vaccine Prepared from Macacus Philippinensis," American Journal of Tropical Medicine and Hygiene, Vol. 11, 1931, pp. 325-336.

[98] R. L. Holt and J. H. Kintner, "Notes on Dengue," Philippine Journal of Science, Vol. 46, 1931, pp. 593-599.

[99] P. M. Ashburn and C. F. Craig, "Experimental Investigations Regarding the Etiology of Dengue," Journal of Infectious Diseases, Vol. 4, 1907, pp. 440-475.

[100] S. Hotta, "Some Immunological Properties of Dengue Virus Cultivated in Tissue Culture," Annals of Tropical Medicine and Parasitology, Vol. 51, No. 3, 1957, pp. 249-255.

[101] W. R. Dorrance, J. W. Frankel, I. Gordon, P. R. Patterson, R. W. Schlesinger and J. W. Winter, "Clinical and Serologic Response of Man to Immunization with Attenuated Dengue and Yellow Fever Viruses," Journal of Immunology, Vol. 77, No. 5, 1956, pp. 352-364.

[102] C. L. Wisserman, B. H. Sweet Jr., E. C. Rosenzweig and O. R. Eylar, "Attenuated Living Type 1 Dengue Vaccines," American Journal of Tropical Medicine and Hygiene, Vol. 12, 1963, pp. 620-623.

[103] J. A. Bellanti, A. T. Bourke, E. L. Buescher, F. C. Cadigan, G. A. Cole, Y. El Batawi, et al., "Report of Dengue Vaccine Field Trial in the Caribbean, 1963: A Collaborative Study," Bulletin of World Health Organization, Vol. 35, No. 1, 1966, p. 93.

[104] W. M. Hammon, A. Rudnick and G. E. Sather, "Viruses Associated with Epidemic Hemorrhagic Fevers of the Philippines and Thailand," Science, Vol. 131, 1960, pp. 1102-1103.

[105] WHO, "Summaries of Papers Presented at the WHO Inter-Regional Seminar on Mosquito-Borne Haemorrhagic Fevers in the South-East Asia and Western Pacific Regions," Bulletin of World Health Organization, Vol. 35, No. 1, 1966, pp. 37-94.
[106] D. J. Gubler, "Dengue/Dengue Haemorrhagic Fever: History and Current Status," Novartis Foundation Symposium, Vol. 277, 2006, pp. 3-16.

[107] WHO, "Guide for Diagnosis, Treatment and Control of Dengue Hemorrhagic Fever," World Health Organization, Manila, 1980.

[108] WHO, "Dengue Vaccine Development: The Role of the WHO South-East Asia Regional Office," New Delhi, 2010, pp. 1-8.

[109] A. P. Durbin and S. S. Whitehead, "Dengue Vaccine Candidates in Development," Current Topics in Microbiology and Immunology, Vol. 338, 2010, pp. 129-143.

[110] W. H. Bancroft, R. M. Scott, K. H. Eckels, C. H. Hoke, T. E. Simms Jr., K. D. Jesrani, et al., "Dengue Virus Type 2 Vaccine: Reactogenicity and Immunogenicity in Soldiers," Journal of Infectious Diseases, Vol. 149, No. 6, 1984, pp. 1005-1010. doi:10.1093/infdis/149.6.1005

[111] K. H. Eckels, R. M. Scott, W. H. Bancroft, J. Brown, D. R. Dubois, P. L. Summers, et al., "Selection of Attenuated Dengue 4 Viruses by Serial Passage in Primary Kidney Cells. V. Human Response to Immunization with a Candidate Vaccine Prepared in Fetal Rhesus Lung Cells," American Journal of Tropical Medicine and Hygiene, Vol. 33, No. 4, 1984, pp. 684-689.

[112] N. Bhamarapravati, S. Yoksan, T. Chayaniyayothin, S. Angsubphakorn and A. Bunyaratvej, "Immunization with a Live Attenuated Dengue-2-Virus Candidate Vaccine (16681-PDK 53): Clinical, Immunological and Biological Responses in Adult Volunteers," Bulletin of World Health Organization, Vol. 35, No. 2, 1987, pp. 189-195.

[113] N. Bhamarapravati and S. Yoksan, "Study of Bivalent Dengue Vaccine in Volunteers," Lancet, Vol. 1, No. 8646, p. 1077. doi:10.1016/S0140-6736(89)92471-9

[114] D. W. Vaughn, C. H. Hoke Jr., S. Yoksan, R. LaChance, B. L. Innis, R. M. Rice, et al., "Testing of a Dengue 2 Live-Attenuated Vaccine (Strain 16681 PDK 53) in Ten American Volunteers," Vaccine, Vol. 14, No. 4, 1996, pp. 329-336. doi:10.1016/0264-410X(95)00167-Y

[115]N. Jirakanjanakit, M M. Khin, S. Yoksan and N. Bhamarapravati, "Dynamics of Susceptibility and Transmissibility of the Live, Attenuated, Candidate Vaccines Dengue-1 PDK13, Dengue-3 PGMK30F3, and Dengue-4 PDK48 after Oral Infection in Aedes Aegypti," American Journal of Tropical Medicine and Hygiene, Vol. 61, No. 4, 1999, pp. 672-676.

[116] J. Rabablert, T. Dharakul, S. Yoksan and N. Bhamarapravati, "Dengue Virus Specific T Cell Responses to Live Attenuated Monovalent Dengue-2 and Tetravalent Dengue Vaccines," Asian Pacific Journal of Allergy Immunology, Vol. 18, No. 4, 2000, pp. 227-235.

[117] A. P. Durbin, B. D. Kirkpatrick, K. K. Pierce, A. C. Schmidt and S. S. Whitehead, "Development and Clinical Evaluation of Multiple Investigational Monovalent DENV Vaccines to Identify Components for Inclusion in a Live Attenuated Tetravalent DENV Vaccine," Vaccine, Vol. 29, No. 42, 2011, pp. 7242-7250. doi:10.1016/j.vaccine.2011.07.023 
[118] J. R. Danko, C. G. Beckett and K. R. Porter, "Development of Dengue DNA Vaccines," Vaccine, Vol. 29, No. 42, 2011, pp. 7261-7266. doi:10.1016/j.vaccine.2011.07.019

[119] B. A. Coller, D. E. Clements, A. J. Bett, S. L. Sagar and J. H. Ter Meulen, "The Development of Recombinant Subunit Envelope-Based Vaccines to Protect against Dengue Virus Induced Disease," Vaccine, Vol. 29, No. 42, 2011, pp. 7267-7275. doi:10.1016/j.vaccine.2011.07.021

[120] J. E. Osorio, C. Y. Huang, R. M. Kinney and D. T. Stinchcomb, "Development of DENVax: A Chimeric Dengue-2 PDK-53-Based Tetravalent Vaccine for Protection against Dengue Fever," Vaccine, Vol. 29, No. 42, 2011, pp. 7251-7260. doi:10.1016/j.vaccine.2011.07.020

[121] S. J. Thomas and T. P. Endy, "Critical Issues in Dengue Vaccine Development," Current Opinion in Infectious Diseases, Vol. 24, No. 5, 2011, pp. 442-450. doi:10.1097/QCO.0b013e32834a1b0b

[122] L. Rosen, “The Emperor's New Clothes Revisited, or Reflections on the Pathogenesis of Dengue Hemorrhagic Fever," American Journal of Tropical Medicine and Hygiene, Vol. 26, No. 3, 1977, pp. 337-343.

[123] L. Thomas, O. Verlaeten, A. Cabie, S. Kaidomar, V. Moravie, J. Martial, et al., "Influence of the Dengue Serotype, Previous Dengue Infection, and Plasma Viral Load on Clinical Presentation and Outcome during a Dengue-2 and Dengue-4 Co-Epidemic," American Journal of Tropical Medicine and Hygiene, Vol. 78, No. 6, 2008, pp. 990998.

[124] N. Sangkawibha, S. Rojanasuphot, S. Ahandrik, S. Viriyapongse, S. Jatanasen, V. Salitul, et al., "Risk Factors in Dengue Shock Syndrome: A Prospective Epidemiologic Study in Rayong, Thailand. I. The 1980 Outbreak," American Journal of Epidemiology, Vol. 120, No. 5, 1984, pp. 653-669.

[125] K. T. Thai, T. Q. Binh, P. T. Giao, H. L. Phuong, Q. Hung, N. Van Nam, et al., "Seroprevalence of Dengue Antibodies, Annual Incidence and Risk Factors among Children in Southern Vietnam," Tropical Medicine and International Health, Vol. 10, No. 4, 2005, pp. 379-386. doi:10.1111/j.1365-3156.2005.01388.x

[126] A. N. Theofilopoulos, "Evaluation and Clinical Significance of Circulating Immune Complexes," Progress in Clinical Immunology, Vol. 4, 1980, pp. 63-106.

[127] W. K. Wang, H. L. Chen, C. F. Yang, S. C. Hsieh, C. C. Juan, S. M. Chang, et al., "Slower Rates of Clearance of Viral Load and Virus-Containing Immune Complexes in Patients with Dengue Hemorrhagic Fever," Clinical Infectious Diseases, Vol. 43, No. 8, 2006, pp. 1023-1030. doi:10.1086/507635

[128] Y. W. Lin, K. J. Wang, H. Y. Lei, Y. S. Lin, T. M. Yeh, H. S. Liu, et al., "Virus Replication and Cytokine Production in Dengue Virus-Infected Human B Lymphocytes," Journal of Virology, Vol. 76, No. 23, 2002, pp. 1224212249. doi:10.1128/FJVI.76.23.12242-12249.2002

[129] H. Bielefeldt-Ohmann, "Analysis of Antibody-Independent Binding of Dengue Viruses and Dengue Virus En- velope Protein to Human Myelomonocytic Cells and B Lymphocytes," Virus Research, Vol. 57, No. 1, 1998, pp. 63-79. doi:10.1016/S0168-1702(98)00087-2

[130] I. Kurane, D. Hebblewaite, W. E. Brandt and F. A. Ennis, "Lysis of Dengue Virus-Infected Cells by Natural CellMediated Cytotoxicity and Antibody-Dependent CellMediated Cytotoxicity," Journal of Virology, Vol. 52, No. 1, 1984, pp. 223-230.

[131] A. N. Theofilopoulos, W. E. Brandt, P. K. Russell and F. T. Dixon, "Replication of Dengue-2 Virus in Cultured Human Lymphoblastoid Cells and Subpopulations of Human Peripheral Leukocytes," Journal of Immunology, Vol. 117, No. 3, 1976, pp. 953-961.

[132] T. Takasaki, K. Takada and I. Kurane, "Electron Microscopic Study of Persistent Dengue Virus Infection: Analysis Using a Cell Line Persistently Infected with Dengue-2 Virus," Intervirology, Vol. 44, No. 1, 2001, pp. 48-54.

[133] S. Blackley, Z. Kou, H. Chen, M. Quinn, R. C. Rose, J. J. Schlesinger, et al., "Primary Human Splenic Macrophages, but Not T or B Cells, Are the Principal Target Cells for Dengue Virus Infection in Vitro," Journal of Virology, Vol. 81, No. 24, 2007, pp. 13325-13334. doi:10.1128/FJVI.01568-07

[134] Z. Kou, M. Quinn, H. Chen, W. W. Rodrigo, R. C. Rose, J. J. Schlesinger, et al., "Monocytes, but Not T or B Cells, Are the Principal Target Cells for Dengue Virus (DV) Infection among Human Peripheral Blood Mononuclear Cells," Journal of Medical Virology, Vol. 80, No. 1, 2008, pp. 134-146. doi:10.1002/jmv.21051

[135] A. D. King, A. Nisalak, S. Kalayanrooj, K. S. Myint, K. Pattanapanyasat, S. Nimmannitya, et al., "B Cells Are the Principal Circulating Mononuclear Cells Infected by Dengue Virus," Southeast Asian Journal of Tropical Medicine and Public Health, Vol. 30, No. 4, 1999, pp. 718728.

[136] W. Jampangern, K. Vongthoung, A. Jittmittraphap, S. Worapongpaiboon, K. Limkittikul, A. Chuansumrit, et al., "Characterization of Atypical Lymphocytes and Immunophenotypes of Lymphocytes in Patients with Dengue Virus Infection," Asian Pacific Journal of Allergy Immunology, Vol. 25, No. 1, 2007, pp. 27-36.

[137] M. O. Baclig, L. T. Gervacio, L. A. Suarez, C. C. Buerano, R. R. Matias, A. Kumatori, et al., "Flow Cytometric Analysis of Dengue Virus-Infected Cells in Peripheral Blood," Southeast Asian Journal of Tropical Medicine and Public Health, Vol. 41, No. 6, 2010, pp. 1352-1358.

[138] U. C. Chaturvedi, M. I. Shukla, M. Pahwa and A. Mathur, "Inhibition of B \& Helper T Lymphocytes by Dengue Virus-Induced Suppressor Factor," Indian Journal of Medical Research, Vol. 82, 1985, pp. 471-474.

[139] M. J. Gilbreath, K. Pavanand, R. P. MacDermott, M. Ussery, D. S. Burke, S. Nimmannitya, et al., "Cold-Reactive Immunoglobulin M Antilymphocyte Antibodies Directed against B Cells in Thai Children with Dengue Hemorrhagic Fever," Journal of Clinical Microbiology, Vol. 17, No. 4, 1983, pp. 672-676. 
[140] I. Kurane, D. Hebblewaite and F. A. Ennis, "Characterization with Monoclonal Antibodies of Human Lymphocytes Active in Natural Killing and Antibody-Dependent Cell-Mediated Cytotoxicity of Dengue Virus-Infected Cells," Immunology, Vol. 58, No. 3, 1986, pp. 429-436.

[141] J. Srinivasappa, J. Saegusa, B. S. Prabhakar, M. K. Gentry, M. J. Buchmeier, Y. J. Wiktor, et al., "Molecular Mimicry: Frequency of Reactivity of Monoclonal Antiviral Antibodies with Normal Tissues," Journal of Virology, Vol. 57, No. 1, 1986, pp. 397-401.

[142] M. B. Oldstone, "Molecular Mimicry and Immune-Mediated Diseases," FASEB Journal, Vol. 12, No. 13, 1998, pp. 1255-1265.

[143] N. R. Rose and I. R. Mackay, "Molecular Mimicry: A Critical Look at Exemplary Instances in Human Diseases," Cellular and Molecular Life Science, Vol. 57, No. 4, 2000, pp. 542-551.

[144] L. J. Markoff, B. L. Innis, R. Houghten and L. S. Henchal, "Development of Cross-Reactive Antibodies to Plasminogen during the Immune Response to Dengue Virus Infection," Journal of Infectious Diseases, Vol. 164, No. 2, 1991, pp. 294-301. doi:10.1093/infdis/164.2.294

[145] Y. S. Lin, T. M. Yeh, C. F. Lin, S. W. Wan, Y. C. Chuang, T. K. Hsu, et al., "Molecular Mimicry between Virus and Host and Its Implications for Dengue Disease Pathogenesis," Experimental Biology and Medicine (Maywood), Vol. 236, No. 5, 2011, pp. 515-523. doi:10.1258/ebm.2011.010339

[146] H. J. Cheng, C. F. Lin, H. Y. Lei, H. S. Liu, T. M. Yeh, Y. H. Luo YH, et al., "Proteomic Analysis of Endothelial Cell Autoantigens Recognized by Anti-Dengue Virus Nonstructural Protein 1 Antibodies," Experimental Biology and Medicine (Maywood), Vol. 234, No. 1, 2009, pp. 63-73. doi:10.3181/0805-RM-147

[147] C. F. Lin, S. W. Wan, H. J. Cheng, H. Y. Lei and Y. S. Lin, "Autoimmune Pathogenesis in Dengue Virus Infection," Viral Immunology, Vol. 19, No. 2, 2006, pp. 127132. doi:10.1089/vim.2006.19.127

[148] R. A. Ezekowitz and S. Gordon, "Alterations of Surface Properties by Macrophage Activation: Expression of Receptors for Fc and Mannose-Terminal Glycoproteins and Differentiation Antigens," Contemporary Topics in Immunobiology, Vol. 13, 1984, pp. 33-56.

[149] M. Stein, S. Keshav, N. Harris and S. Gordon, "Interleukin 4 Potently Enhances Murine Macrophage Mannose Receptor Activity: A Marker of Alternative Immunologic Macrophage Activation," Journal of Experimental Medicine, Vol. 176, No. 1, 1992, pp. 287-292.

[150] S. Goerdt, O. Politz, K. Schledzewski, R. Birk, A. Gratchev, P. Guillot, et al., "Alternative Versus Classical Activation of Macrophages," Pathobiology, Vol. 67, No. 5-6, 1999, pp. 222-226.

[151] S. Goerdt and C. E. Orfanos, "Other Functions, Other Genes: Alternative Activation of Antigen-Presenting Cells," Immunity, Vol. 10, No. 2, 1999, pp. 137-142. doi:10.1016/S1074-7613(00)80014-X

[152] F. S. Sutterwala, G. J. Noel, R. Clynes and D. M. Mosser,
"Selective Suppression of Interleukin-12 Induction after Macrophage Receptor Ligation," Journal of Experimental Medicine, Vol. 185, No. 11, 1997, pp. 1977-1985.

[153]F. S. Sutterwala, G. J. Noel, P. Salgame and D. M. Mosser, "Reversal of Proinflammatory Responses by Ligating the Macrophage Fcgamma Receptor Type I," Journal of Experimental Medicine, Vol. 188, No. 1, 1998, pp. 217-222.

[154] C. F. Anderson and D. M. Mosser, "Cutting Edge: Biasing Immune Responses by Directing Antigen to Macrophage Fc Gamma Receptors," Journal of Immunology, Vol. 168, No. 8, 2002, pp. 3697-3701.

[155] G. J. Randolph, "Immunology. No Need to Coax Monocytes," Science, Vol. 332, No. 6035, 2011, pp. 1268-1269. doi: $10.1126 /$ science. 1208480

[156] S. J. Jenkins, D. Ruckerl, P. C. Cook, L. H. Jones, F. D. Finkelman, N. van Rooijen, et al., "Local Macrophage Proliferation, Rather than Recruitment from the Blood, Is a Signature of TH2 Inflammation," Science, Vol. 332, No. 6035, 2011, pp. 1284-1288. doi:10.1126/science. 1204351

[157] D. M. Mosser, "The Many Faces of Macrophage Activation," Journal of Leukocyte Biology, Vol. 73, No. 2, 2003, pp. 209-212. doi:10.1189/jlb.0602325

[158] C. F. Lin, H. Y. Lei, A. L. Shiau, H. S. Liu, T. M. Yeh, S. H. Chen, et al., "Endothelial Cell Apoptosis Induced by Antibodies against Dengue Virus Nonstructural Protein 1 via Production of Nitric Oxide," Journal of Immunology, Vol. 169, No. 2, 2002, pp. 657-664.

[159] C. C. Liu, K. J. Huang, Y. S. Lin, T. M. Yeh, H. S. Liu and H. Y. Lei, "Transient CD4/CD8 Ratio Inversion and Aberrant Immune Activation during Dengue Virus Infection," Journal of Medical Virology, Vol. 68, No. 2, pp. 241-252. doi:10.1002/jmv.10198

[160] T. H. Nguyen, H. Y. Lei, T. L. Nguyen, Y. S. Lin, K. J. Huang, B. L. Le, et al., "Dengue Hemorrhagic Fever in Infants: A Study of Clinical and Cytokine Profiles," Journal of Infectious Diseases, Vol. 189, No. 2, 2004, pp. 221-232. doi:10.1086/380762

[161] H. Y. Lei, T. M. Yeh, H. S. Liu, Y. S. Lin, S. H. Chen and C. C. Liu, "Immunopathogenesis of Dengue Virus Infection," Journal of Biomedical Science, Vol. 8, No. 5, 2001, pp. 377-388. doi:10.1007/BF02255946

[162]H. Y. Lei, "Transient Hemophagocytic Activity in Dengue Immunopathogenesis," Journal of Formosan Medical Association, Vol. 108, No. 8, 2009, pp. 595-598. doi:10.1016/S0929-6646(09)60379-X

[163] I. J. Su, "Perspectives on the Pathogenesis and Therapy of Hemophagocytic Syndrome," Journal of Formosan Medical Association, Vol. 107, No. 4, 2008, pp. 277-280. doi:10.1016/S0929-6646(08)60087-X

[164] M. Leslie, "Cell Biology. Beyond Clotting: The Powers of Platelets," Science, Vol. 328, No. 5978, 2010, pp. 562564. doi:10.1126/science.328.5978.562

[165] J. W. Semple and J. Freedman, "Platelets and Innate Immunity," Cellular and Molecular Life Science, Vol. 67, No. 4, 2009, pp. 499-511. doi:10.1007/s00018-009-0205-1 
[166] P. von Hundelshausen and C. Weber, "Platelets as Immune Cells: Bridging Inflammation and Cardiovascular Disease," Circulation Research, Vol. 100, No. 1, pp. 2740. doi:10.1161/01.RES.0000252802.25497.b7

[167] T. Youssefian, A. Drouin, J. M. Masse, J. Guichard and E. M. Cramer, "Host Defense Role of Platelets: Engulfment of HIV and Staphylococcus Aureus Occurs in a Specific Subcellular Compartment and Is Enhanced by Platelet Activation," Blood, Vol. 99, No. 11, 2002, pp. 4021-4029. doi:10.1182/blood-2001-12-0191

[168] A. S. Weyrich and G. A. Zimmerman, "Platelets: Signaling Cells in the Immune Continuum," Trends in Immunology, Vol. 25, No. 9, 2004, pp. 489-495. doi:10.1016/j.it.2004.07.003

[169] R. Aslam, E. R. Speck, M. Kim, A. R. Crow, K. W. Bang, F. P. Nestel, et al., "Platelet Toll-Like Receptor Expression Modulates Lipopolysaccharide-Induced Thrombocytopenia and Tumor Necrosis Factor-Alpha Production in Vivo," Blood, Vol. 107, No. 2, 2006, pp. 637-641. doi:10.1182/blood-2005-06-2202

[170] N. Li, "Platelet-Lymphocyte Cross-Talk," Journal of Leukocyte Biology, Vol. 85, No. 5, 2008, pp. 1069-1078. doi:10.1189/jlb.0907615

[171] M. Czapiga, A. D. Kirk and J. Lekstrom-Himes, "Platelets Deliver Costimulatory Signals to Antigen-Presenting Cells: A Potential Bridge between Injury and Immune Activation," Experimental Hematology, Vol. 32, No. 2, 2004, pp. 135-139.

[172] B. D. Elzey, J. F. Grant, H. W. Sinn, B. Nieswandt, T. J. Waldschmidt and T. L. Ratliff, "Cooperation between Platelet-Derived CD154 and CD4+ T Cells for Enhanced Germinal Center Formation," Journal of Leukocyte Biology, Vol. 78, No. 1, 2005, pp. 80-84. doi:10.1189/jlb.1104669

[173] S. Sadallah, C. Eken, P. J. Martin and J. A. Schifferli, "Microparticles (Ectosomes) Shed by Stored Human Platelets Downregulate Macrophages and Modify the Development of Dendritic Cells," Journal of Immunology, Vol. 186, No. 11, 2011, pp. 6543-6552. doi:10.4049/jimmunol.1002788

[174] B. D. Elzey, J. Tian, R. J. Jensen, A. K. Swanson, J. R. Lees, S. R. Lentz, et al., "Platelet-Mediated Modulation of Adaptive Immunity. A Communication Link between Innate and Adaptive Immune Compartments," Immunity, Vol. 19, No. 1, 2003, pp. 9-19. doi:10.1016/S1074-7613(03)00177-8

[175] J. W. Semple, J. E. Italiano Jr. and J. Freedman, "Platelets and the Immune Continuum," Nature Reviews Immunology, Vol. 11, No. 4, 2011, pp. 264-274. doi:10.1038/nri2956

[176] M. I. Furman, D. J. Kereiakes, L.A. Krueger, M. N. Mueller, K. Pieper, T. M. Broderick, et al., "LeukocytePlatelet Aggregation, Platelet Surface P-Selectin, and Platelet Surface Glycoprotein IIIa after Percutaneous coronary Intervention: Effects of Dalteparin or Unfractionated Heparin in Combination with Abciximab," American Heart Journal, Vol. 142, No. 5, 2001, pp. 790-798. doi: $10.1067 / \mathrm{mhj} .2001 .119128$
[177] M. P. Gawaz, S. K. Mujais, B. Schmidt and H. J. Gurland, "Platelet-Leukocyte Aggregation during Hemodialysis," Kidney International, Vol. 46, No. 2, 1994, pp. 489-495. doi:10.1038/ki.1994.299

[178] E. Boilard, P. A. Nigrovic, K. Larabee, G. F. Watts, J. S. Coblyn, M. E. Weinblatt, et al., "Platelets Amplify Inflammation in Arthritis via Collagen-Dependent Microparticle Production," Science, Vol. 327, No. 5965, 2010, pp. 580-583. doi:10.1126/science. 1181928

[179] A. Kornberg, N. N. Rao and D. Ault-Riche, "Inorganic Polyphosphate: A Molecule of Many Functions," Annual Review of Biochemistry, Vol. 68, 1999, pp. 89-125. doi:10.1146/annurev.biochem.68.1.89

[180] E. Pavlov, R. Aschar-Sobbi, M. Campanella, R. J. Turner, M R. Gomez-Garcia and A. Y. Abramov, "Inorganic Polyphosphate and Energy Metabolism in Mammalian Cells," Journal of Biological Chemistry, Vol. 285, No. 13, 2010, pp. 9420-9428. doi:10.1074/jbc.M109.013011

[181] F. A. Ruiz, C. R. Lea, E. Oldfield and R. Docampo, "Human Platelet Dense Granules Contain Polyphosphate and Are Similar to Acidocalcisomes of Bacteria and Unicellular Eukaryotes," Journal of Biological Chemistry, Vol. 279, No. 43, 2004, pp. 44250-44257. doi:10.1074/jbc.M406261200

[182] J. Caen and Q. Wu, "Hageman Factor, Platelets and Polyphosphates: Early History and Recent Connection," Journal of Thrombosis and Haemostasis, Vol. 8, No. 8, 2010, pp. 1670-1674. doi:10.1111/j.1538-7836.2010.03893.x

[183] L. Hernandez-Ruiz, I. Gonzalez-Garcia, C. Castro, J. A. Brieva and F. A. Ruiz, "Inorganic Polyphosphate and Specific Induction of Apoptosis in Human Plasma Cells," Haematologica, Vol. 91, No. 9, 2006, pp. 1180-1186.

[184] F. Muller, N. J. Mutch, W. A. Schenk, S. A. Smith, L. Esterl, H. M. Spronk, et al., "Platelet Polyphosphates Are Proinflammatory and Procoagulant Mediators in Vivo," Cell, Vol. 139, No. 6, 2009, pp. 1143-1156. doi:10.1016/j.cell.2009.11.001

[185] S. A. Smith, N. J. Mutch, D. Baskar, P. Rohloff, R. Docampo and J. H. Morrissey, "Polyphosphate Modulates Blood Coagulation and Fibrinolysis," Proceedings of $\mathrm{Na}$ tional Academy of Sciences of the United States of America, Vol. 103, No. 4, 2006, pp. 903-908. doi:10.1073/pnas.0507195103

[186] S. Noisakran, K. Chokephaibulkit, P. Songprakhon, N. Onlamoon, H. M. Hsiao, F. Villinger, et al., "A ReEvaluation of the Mechanisms Leading to Dengue Hemorrhagic Fever," Annals of the New York Academy of Sciences, Vol. 1171, Suppl. 1, 2009, pp. E24-35. doi:10.1111/j.1749-6632.2009.05050.x

[187] S. Noisakran, R. V. Gibbons, P. Songprakhon, A. Jairungsri, C. Ajariyakhajorn, A. Nisalak, et al., "Detection of Dengue Virus in Platelets Isolated from Dengue Patients," Southeast Asian Journal of Tropical Medicine and Public Health, Vol. 40, No. 2, 2009, pp. 253-262.

[188] J. Hombach, "Vaccines against Dengue: A Review of Current Candidate Vaccines at Advanced Development 
Stages," Revista Panamericana De Salud Publica, Vol. 21, No. 4, 2007, pp. 254-260. doi:10.1590/S1020-49892007000300011

[189] T. P. Endy, K. B. Anderson, A. Nisalak, I. K. Yoon, S. Green, A. L. Rothman, et al., "Determinants of Inapparent and Symptomatic Dengue Infection in a Prospective Study of Primary School Children in Kamphaeng Phet, Thailand," PLoS Neglected Tropical Diseases, Vol. 5, No. 3, 2011, p. e975. doi:10.1371/journal.pntd.0000975

[190] S. S. Whitehead, J. E. Blaney, A. P. Durbin and B. R. Murphy, "Prospects for a Dengue Virus Vaccine," Nature Reviews Microbiology, Vol. 5, No. 7, 2007, pp. 518-528. doi:10.1038/nrmicro1690

[191] R. Edelman, "Unique Challenges Faced by the Clinical Evaluation of Dengue Vaccines," Expert Review of Vaccines, Vol. 10, No. 2, 2011, pp. 133-136. doi:10.1586/erv.10.159

[192] S. Anantapreecha, A. A-Nuegoonpipat, S. Prakrong, S. Chanama, A. Sa-Ngasang, P. Sawanpanyalert, et al., "Dengue Virus Cross-Reactive Hemagglutination Inhibition Antibody Responses in Patients with Primary Dengue Virus Infection," Japanese Journal of Infectious Diseases, Vol. 60, No. 5, 2007, pp. 267-270.

[193] A. P. Durbin, S. S. Whitehead, D. Shaffer, D. Elwood, K. Wanionek, B. Thumar, et al., "A Single Dose of the DENV-1 Candidate Vaccine rDEN1Delta30 Is Strongly Immunogenic and Induces Resistance to a Second Dose in a Randomized Trial," PLoS Neglected Tropical Diseases, Vol. 5, No. 8, 2011, p. e1267. doi:10.1371/journal.pntd.0001267

[194] M. Beltramello, K. L. Williams, C. P. Simmons, A. Macagno, L. Simonelli, N. T. Quyen, et al., "The Human Immune Response to Dengue Virus Is Dominated by Highly Cross-Reactive Antibodies Endowed with Neutralizing and Enhancing Activity," Cell Host and Microbe, Vol. 8, No. 3, 2010, pp. 271-283. doi:10.1016/j.chom.2010.08.007

[195] S. B. Halstead, "Neutralization and Antibody-Dependent Enhancement of Dengue Viruses," Advances in Virus Research, Vol. 60, 2003, pp. 421-467.

[196] W. Dejnirattisai, A. Jumnainsong, N. Onsirisakul, P. Fitton, S. Vasanawathana, W. Limpitikul, et al., "Cross-
Reacting Antibodies Enhance Dengue Virus Infection in Humans," Science, Vol. 328, No. 5979, 2010, pp. 745748. doi:10.1126/science. 1185181

[197] K. J. Huang, Y. C. Yang, Y. S. Lin, J. H. Huang, H. S. Liu, T. M. Yeh, et al., "The Dual-Specific Binding of Dengue Virus and Target Cells for the Antibody-Dependent Enhancement of Dengue Virus Infection," Journal of Immunology, Vol. 176, No. 5, 2006, pp. 2825-2832.

[198] E. Chungue, L. Poli, C. Roche, P. Gestas, P. Glaziou and L. J. Markoff, "Correlation between Detection of Plasminogen Cross-Reactive Antibodies and Hemorrhage in Dengue Virus Infection," Journal of Infectious Diseases, Vol. 170, No. 5, 1994, pp. 1304-1307. doi:10.1093/infdis/170.5.1304

[199] M. C. Chen, C. F. Lin, H. Y. Lei, S. C. Lin, H. S. Liu, T. M. Yeh, et al., "Deletion of the C-Terminal Region of Dengue Virus Nonstructural Protein 1 (NS1) Abolishes Anti-NS1-Mediated Platelet Dysfunction and Bleeding Tendency," Journal of Immunology, Vol. 183, No. 3, 2009, pp. 1797-1803. doi:10.4049/jimmunol.0800672

[200] H. J. Cheng, H. Y. Lei, C. F. Lin, Y. H. Luo, S. W. Wan, H. S. Liu, et al., "Anti-Dengue Virus Nonstructural Protein 1 Antibodies Recognize Protein Disulfide Isomerase on Platelets and Inhibit Platelet Aggregation," Molecular Immunology, Vol. 47, No. 2-3, 2009, pp. 398-406. doi:10.1016/j.molimm.2009.08.033

[201] B. Carme, S. Matheus, G. Donutil, O. Raulin, M. Nacher and J. Morvan, "Concurrent Dengue and Malaria in Cayenne Hospital, French Guiana," Emerging Infectious Diseases, Vol. 15, No. 4, 2009, pp. 668-671. doi:10.3201/eid1504.080891

[202] D. Donati, B. Mok, A. Chene, H. Xu, M. Thangarajh, R. Glas, et al., "Increased B Cell Survival and Preferential Activation of the Memory Compartment by a Malaria Polyclonal B Cell Activator," Journal of Immunology, Vol. 177, No. 5, 2006, pp. 3035-3044.

[203] R. Mahoney, L. Chocarro, J. Southern, D. P. Francis, J. Vose and H. Margolis, "Dengue Vaccines Regulatory Pathways: A Report on Two Meetings with Regulators of Developing Countries," PLoS Medicine, Vol. 8, No. 2, 2011, p. e1000418. doi:10.1371/journal.pmed.1000418 